\title{
The safety of nanostructured synthetic amorphous silica (SAS) as a food additive ( $E$ 551)
}

\author{
Claudia Fruijtier-Pölloth ${ }^{1}$ (D)
}

Received: 25 July 2016 / Accepted: 8 September 2016 / Published online: 3 October 2016

(C) Springer-Verlag Berlin Heidelberg 2016

\section{Abstract \\ Key messages}

- Particle sizes of $\mathbf{E} 551$ products are in the micrometre range. The typical external diameters of the constituent particles (aggregates) are greater than 100 nm.

- E 551 does not break down under acidic conditions such as in the stomach, but may release dissolved silica in environments with higher $\mathrm{pH}$ such as the intestinal tract.

- E 551 is one of the toxicologically most intensively studied substances and has not shown any relevant systemic or local toxicity after oral exposure.

Abstract Synthetic amorphous silica (SAS) meeting the specifications for use as a food additive (E 551) is and has always been produced by the same two production methods: the thermal and the wet processes, resulting in E 551 products consisting of particles typically in the micrometre size range. The constituent particles (aggregates) are typically larger than $100 \mathrm{~nm}$ and do not contain discernible primary particles. Particle sizes above $100 \mathrm{~nm}$ are necessary for E 551 to fulfil its technical function as spacer between food particles, thus avoiding the caking of food particles. Based on an in-depth review of the available toxicological information and intake data, it is concluded that the SAS products specified for use as food additive E 551 do not cause adverse effects in oral repeated-dose studies including doses that exceed current OECD guideline recommendations. In particular, there is no evidence for liver toxicity

Dr Claudia Fruijtier-Pölloth

claudia@catsconsultants.com

1 CATS Consultants GmbH, Ussenried 7, 87463 Dietmannsried, Germany after oral intake. No adverse effects have been found in oral fertility and developmental toxicity studies, nor are there any indications from in vivo studies for an immunotoxic or neurotoxic effect. SAS is neither mutagenic nor genotoxic in vivo. In intact cells, a direct interaction of unlabelled and unmodified SAS with DNA was never found. Differences in the magnitude of biological responses between pyrogenic and precipitated silica described in some in vitro studies with murine macrophages at exaggerated exposure levels seem to be related to interactions with cell culture proteins and cell membranes. The in vivo studies do not indicate that there is a toxicologically relevant difference between SAS products after oral exposure. It is noted that any silicon dioxide product not meeting established specifications, and/or produced to provide new functionality in food, requires its own specific safety and risk assessment.

Keywords Synthetic amorphous silica $\cdot$ SAS $\cdot$ Silicon dioxide $\cdot$ E $551 \cdot$ Food safety $\cdot$ Nanostructured

\section{Introduction}

Synthetic amorphous silica (SAS), also known as synthetic amorphous silicon dioxide, has been used as a direct food additive for decades. Both the Joint FAO/WHO Expert Committee on Food Additives (JECFA) and the EU Scientific Committee on Food (SCF, now EFSA) have previously evaluated silicon dioxide as a food additive (E 551, INS 551) and established an acceptable daily intake (ADI) "not specified" which generally refers to substances of very low toxicity. The more recent designation of SAS as a nanostructured material has, however, raised concerns with regard to its safety as a food additive and has prompted several new investigations as well as safety and 
risk assessments by various research groups. This article has therefore been written to specifically address these new safety concerns, including the possibility of low-dose effects, toxicity of potentially released nanoparticles, liver toxicity, and immunotoxicity.

\section{Background: SAS as a direct food additive (E 551, INS 551)}

Specific purity criteria are defined for the use of SAS as a food additive. In the European Union (EU), the specific purity criteria are defined in Commission Regulation (EU) No 231/2012. SAS meeting these criteria is permitted under the name of "Silicon dioxide" or "E 551" as direct food additive in accordance with Annex II and Annex III to Regulation (EC) No. 1333/2008 (as amended) as an anticaking agent and a carrier. The specific criteria in Commission Regulation (EU) No. 231/2012 also contain the two production methods with which SAS is made: the thermal process and the wet process. These processes result in solid SAS products of identical chemical composition either as anhydrous products (pyrogenic SAS, produced by the thermal route) or as hydrated products (precipitated silica, silica gel, or hydrous silica; all produced by the wet route). An overview of SAS products which are used as a food additive (E 551) is presented in Table 1.

SAS as used as a food additive (E 551, INS 551) is marketed as a white fluffy powder or as granules which, in the case of hydrated silica, may contain surface- or pore-bound water. Importantly, E 551 is not marketed as a suspension of stabilised nanoparticles (colloidal silica). Since the beginning of its commercialisation in the 1950s (ECETOC 2006), SAS is produced by the same two manufacturing processes, i.e. the thermal process and the wet process. These two production methods have been described earlier (EC 2007). The resulting products are chemically identical; products made by the wet process may contain sodium salts as impurities resulting from the manufacturing process based on sodium silicates. E 551 is placed on the market in solid form only and should therefore not be confused with stabilised suspensions of silica nanoparticles (often referred to as colloidal silica). The latter are manufactured by different processes, e.g. the Stöber method, and do not meet the EU specifications for E 551. These colloidal silica suspensions are not regulated as direct food additive (E 551) in the EU, but may be used as processing aid in EU countries under national legislation and be marketed as food grade.

E 551 is not produced in a nano- and non-nanoform, nor does it exist in a nano- and non-nanoform. E 551 is not engineered to have novel properties, and the particle size distributions of aggregates and agglomerates of today's products are in fact identical to those produced in earlier decade. Since the technical function of E 551 is to act as a spacer between food components in order for them to remain in a free state, nanosized particles are actually not desired because they are too small to enable this effect. The spacer function can only be achieved by the silica aggregates and agglomerates having size ranges which are typically greater than $100 \mathrm{~nm}$ (it is noted that there are studies published, where almost spherical corn starch host particles with a smooth surface were used and where adsorbate diameters of anti-caking agents down to $40-50 \mathrm{~nm}$ are mentioned (Kurfe $\beta$ et al. 2005; Müller et al. 2008; Ruppel et al. 2009). Such powders do, however, not represent the typical host powder where larger spacers are required to fill cavities). Regulatory aspects relating to the EU food sector have recently been summarised and are therefore not re-iterated here (Amenta et al. 2015).

\section{E 551 particle morphology and size}

E 551 is produced as fluffy fine powder or granules in the micrometre size range. Figure 1 (left) shows a ca. 20-30 micrometre granule as typically contained in products delivered to the customer. Powders and granules consist of

Table 1 Overview on synthetic amorphous silica products used as a food additive (E 551)

\begin{tabular}{llllll}
\hline Product & $\begin{array}{l}\text { EU name } \\
\text { (Reg. 231/2012) }\end{array}$ & EINECS no & CAS no., generic & CAS no., specific & $\begin{array}{l}\text { Chemical abstracts } \\
\text { index name }\end{array}$ \\
\hline Pyrogenic silica & Fumed silica & $231-545-4$ & $7631-86-9$ & $112945-52-5$ & $\begin{array}{c}\text { Silica, amorphous, } \\
\text { fumed; crystalline- } \\
\text { free }\end{array}$ \\
Hydrated silica & Precipitated silica & $231-545-4$ & $7631-86-9$ & $112926-00-8$ & $\begin{array}{c}\text { Synthetic amorphous } \\
\text { silica, precipitated; } \\
\text { crystalline-free }\end{array}$ \\
& $\begin{array}{c}\text { Silica gel, hydrous } \\
\text { silica }\end{array}$ & $231-545-4$ & $7631-86-9$ & $112926-00-8$ & $\begin{array}{c}\text { Synthetic amorphous } \\
\text { silica, gel; crystal- } \\
\text { line-free }\end{array}$ \\
\hline
\end{tabular}

a JRC EU Joint Research Centre 

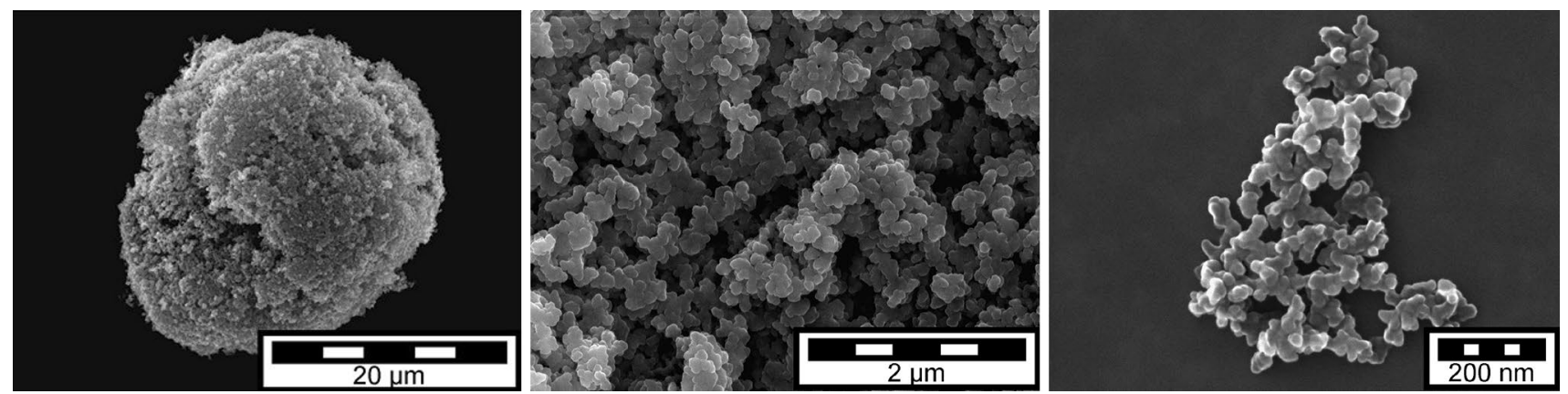

Fig. 1 SEM images of pyrogenic silica granule, agglomerate, and aggregate (@Evonik Resource Efficiency GmbH)

agglomerated aggregates (see Fig. 1, middle). Agglomerates can be separated into aggregates (see Fig. 1, right) by applying high energy or shear force techniques such as prolonged ultrasonication or mixing.

These aggregates are the smallest discrete entities in $\mathrm{E}$ 551 ; they are three-dimensional units with a high degree of branching. The typical external size of SAS aggregates is greater than $100 \mathrm{~nm}$; separation of aggregates into "primary particles" is impossible (Dünisch 2005; ECETOC 2006; Gray and Muranko 2006; Ma-Hock et al. 2007; Maier et al. 2006). The aggregates can therefore be designated as the constituent particles of E 551. Primary particles-according to the ISO definition "the original source particles of agglomerates or aggregates or mixtures of the two"-are not discernible anymore in E 551 after completion of the synthesis process. All primary particles have been fused together to form the three-dimensional aggregates. No inner boundaries are visible within SAS aggregates (Albers et al. 2015), see Fig. 2.

Because there are no discernible "primary particles" anymore in the $\mathrm{E} 551$ product, it is impossible to determine their size or size distribution. With regard to aggregate sizes and aggregate size distributions, several techniques are usually necessary for a reliable volume- or mass-based size determination. Generally, external aggregate sizes are greater than $100 \mathrm{~nm}$ (data on file), but sample preparation methods and the analytical method have a profound influence on the results (Barahona et al. 2016). If not used in combination with other techniques, 2-dimensional ultrascopy methods (scanning electron microscopy, SEM, or transmission electron microscopy, TEM), in particular, are not suitable to determine SAS aggregate size distributions. In the case of branched aggregates, such as SAS, 2-dimensional SEM and TEM generate so-called equivalent diameters and an apparent (i.e. not a real) property of SAS, namely that it would contain small isolated particles in the nanosize range. The European Commission JRC report on the requirements on measurements for the implementation of the European Commission definition of the term "nanomaterial" reads (page 22 of the report) (Linsinger et al. 2012): “...It has been suggested that electron microscopy (EM) [in particular, transmission electron microscopy
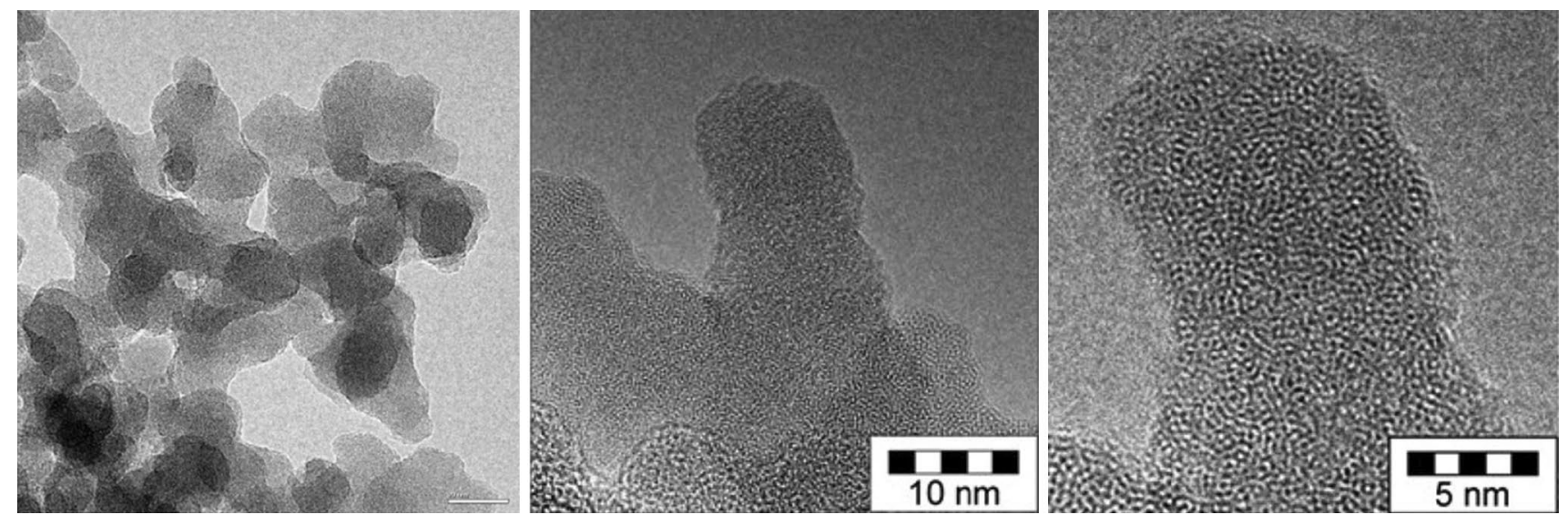

Fig. 2 TEM images of part of a pyrogenic silica aggregate (left) and enlarged view of inner structures at the nanometre scale (middle, right) (CEvonik Resource Efficiency GmbH) 
(TEM)] provides the most accurate particle size values. This, however, relies on the assumption that a projected area equivalent size is the 'true size'. Unfortunately, this size is deduced from a $2 \mathrm{D}$ image and is independent of the thickness of the particle in the third dimension. A second disadvantage is that it does not correspond to common understanding: the area equivalent size of a highly branched particle may be very small, whereas it can extend widely, reaching a large external dimension". It is furthermore known that the preparation of representative samples is a major source of uncertainty, and that the automated counting of digitally processed TEM and SEM images generates artificially high numbers of particles in the nanosize range when agglomerates are present. Reports based solely on TEM/SEM methodology and claiming that $100 \%$ of E 551 would be in the nanosize range are therefore misleading (Agir pour l'environnement 2016). Currently, there are no reliable standardised analytical methods available to characterise the number weighted particle size distribution of SAS in the nanosize range below $100 \mathrm{~nm}$. Efforts to establish such distributions suffer from the assumption of a spherical particle shape, see, for example, (Barahona et al. 2016; Contado et al. 2016), which is not correct in the case of $\mathrm{E} 551$ as the $\mathrm{E} 551$ aggregate is not a sphere.

\section{Exposure and intake estimates}

Information on relevant food categories and use levels of E 551 were recently collected by members of the Association of Synthetic Amorphous Silica Producers (ASASP) from customers and from food associations. This was the only way for the raw material suppliers to gain this information. According to the survey, the uses covered were all direct uses and carry-over into foods. The collected data were used to generate intake estimates with the Comprehensive European Dietary Exposure Model (CEDEM) (Tennant 2016) and resulted in population average intake estimates of silicon dioxide from its use as a food additive (E 551) ranging between 0.28 and $4.53 \mathrm{mg} \mathrm{E} 551 / \mathrm{kg}$ bw/day. The highest intake estimate was at $12.7 \mathrm{mg} / \mathrm{kg}$ bw/day for children in Bulgaria which is likely to be an overestimate because it assumes $100 \%$ occurrence of E 551 in all food categories. Earlier, a daily exposure of $9.4 \mathrm{mg} / \mathrm{kg}$ bw/day was estimated for the Dutch population based on expert judgement of consumption frequencies and amounts (Dekkers et al. 2011).

For the total dietary intake of E 551, not only the amount of E 551 in food has to be estimated, but also potential intake from other sources. In addition to its use as a food additive, E 551 is also used in cosmetics (e.g. as abrasion additive in toothpastes), in pharmaceuticals (e.g. as free-flow additive, carrier, or retardant agent and as tableting aid), and in dietary supplements (e.g. as dispersive medium for vitamins). Some naturally occurring foods, particularly of plant origin, contain high amounts of biogenic silicon dioxide, amongst them cereals, particularly oats and barley, wheat flour, rice, and, especially, beer (see, for example, EFSA 2009; Jugdaohsingh 2007; Powell et al. 2005). The difficulty in analysing food matrices for E 551 particles and to differentiate these from the high natural silicon and silicon dioxide (silica) content of many foods make a direct measurement difficult. Usually dissolved silicon is extracted and measured, but there are currently no validated routine methods for the quantitative determination of silicon dioxide particles in food (Singh et al. 2014). Current laboratory methods for silica particle analysis are only validated for the analysis in relatively simple and defined matrices and often have a low sensitivity in the size range below $200 \mathrm{~nm}$ and a low reproducibility.

In food supplements, silica is added up to a level of $700 \mathrm{mg}$ silicon/day (EFSA 2009). Estimates on the intake of $\mathrm{E} 551$ contained in pharmaceutical formulations are not available. Very low levels $(<0.2 \%)$ are required when used as a glidant for tablets, the most common medicinal application. Toothpaste may, however, contain relatively high amounts of E 551, which in part may be swallowed.

An overview of intakes from different sources is provided in Table 2.

\section{Bioavailability after oral intake}

Due to the changing and complex conditions in the gastrointestinal tract, including different $\mathrm{pH}$ environments, the influence of food matrices, microflora, mucus, and peristaltic movements, it is difficult to fully predict the fate of E 551 particles after oral ingestion. Due to analytical difficulties mainly because of high environmental background silica levels, no studies are available in which unlabelled silica particles were quantitatively analysed in body fluids and organs after oral exposure. Results of in vitro digestion studies (Maier et al. 2013; Peters et al. 2012; Sakai-Kato et al. 2014) have shown a resistance of silica agglomerates and aggregates to break down under conditions of low $\mathrm{pH}$ such as in the stomach. Dissolution may increase in the more alkaline $\mathrm{pH}$ environments of the small intestine and in the colon, and values of up to $20 \mathrm{wt} \%$ have been reported for the dissolution in the intestinal content (van der Zande et al. 2014). These findings are in agreement with biodurability tests performed with SAS in Caco- 2 medium by the European Joint Research Centre (JRC 2013). A fraction of $\mathrm{E} 551$ may therefore be taken up in form of orthosilicic acid by the intestinal tract. If absorbed, particles are usually sequestered in Peyer's patch macrophages, and those that 
Table 2 Silicon and Silicon dioxide (silica particle) intakes from different sources

\begin{tabular}{|c|c|c|c|c|}
\hline & Source & Daily intake & & References \\
\hline \multirow[t]{6}{*}{ Silicon $(\mathrm{Si})$} & & mg/day & $\mathrm{mg} / \mathrm{kg}$ bw/day & \\
\hline & $\begin{array}{l}\text { Food (naturally and from additives), } \\
\text { Western population }\end{array}$ & $20-50$ & $0.3-0.8$ & $\begin{array}{l}\text { EFSA (2004), Jugdaohsingh (2007) and } \\
\text { Jurkić et al. (2013) }\end{array}$ \\
\hline & Food (mainly plant based) & $140-204$ & & Cited in Jugdaohsingh (2007) \\
\hline & Food (BE) & $18.6 \pm 8.5$ & & Robberecht et al. (2009) \\
\hline & Beer (1 litre) & $6.4-56.5$ & & Casey and Bamforth (2010) \\
\hline & Dietary supplements & $1-75$, up to 700 & $0.017-1.5$, up to 12 & EFSA $(2004,2009)$ \\
\hline \multicolumn{5}{|l|}{ Silica $\left(\mathrm{SiO}_{2}\right)$} \\
\hline & E 551 in food (NL) & $\begin{array}{l}658 \\
124 \text { (“nanosilica”) }\end{array}$ & $\begin{array}{l}9.4 \text { ("dissolved") } \\
1.8 \text { ("nanosilica"a) }\end{array}$ & Dekkers et al. (2011) \\
\hline & E 551 in food & & $0.28-4.53$ & (FCRA 2016) \\
\hline & Dietary supplements & up to 1500 & up to 25 & EFSA (2009) \\
\hline & Mixed silicate particles in food & $35(0-254)$ & & Lomer et al. (2004) \\
\hline & Toothpaste containing $30 \%$ SAS & 41 & 0.65 & Using intake data from $(\operatorname{SCCS} 2015)^{\mathrm{b}}$ \\
\hline & E 551 in medicines & 0.2 & & $\begin{array}{l}\text { Based on two oral tablets/day à } 0.5 \mathrm{~g} \text { with } \\
0.02 \% \text { E } 551\end{array}$ \\
\hline
\end{tabular}

a Particle size range 1-200 nm

b (SCCS 2015): daily intake, toothpaste $=138 \mathrm{mg}$ or $2.16 \mathrm{mg} / \mathrm{kg}$ bw

escape sequestration are transported by lymph rather than by portal blood. It has been suggested that the nanosized fraction of ingested particles could directly pass through regular epithelial cells to underlying dendritic cells (Howe et al. 2014), but there are no studies demonstrating this for SAS. Given the high exposure to natural silica in foods, and the lack of any signs of an immunotoxic potential of SAS in repeated-dose animal studies, an adverse effect by this mechanism is unlikely.

In an oral 28-d study in rats with food-grade precipitated silica, mesenteric lymph nodes, liver, and kidney were investigated by electron microscopy for silica particles. Occasionally, cells of the mesenteric lymph nodes, liver, and kidneys of all animals of the untreated group and of the amorphous silica-treated group showed electron dense structures. These electron dense structures were found in vacuoles in the cytoplasm and were characterised as "irregular homogenous to fine granular material". The granular structures measured only few nanometres, but did not show the shape or appearance of amorphous silica. These results show the presence of particulate matter in the nanosize range in ALL animals, i.e. including those NOT exposed to precipitated silica (CEFIC 2011). Silica particles could also not be found in the livers of rats exposed for 28 or 84 days to food-grade pyrogenic silica (van der Zande et al. 2014). Silicon ( $\mathrm{Si}$ ) concentrations were not increased in the investigated organs (liver, kidney, testis, brain) even after high-dose exposure for up to 84 days. An increase in Si levels was only found in the spleen of rats exposed to an oral dose of $2500 \mathrm{mg} / \mathrm{kg}$ bw/day (for 84 days) (van der Zande et al. 2014), a dose level that exceeds the current recommendations in OECD guidelines by a factor of 2.5. If taken up by cells, SAS particles are usually located in vesicles and endocytic compartments, and also along actin fibres and nuclear invaginations (Tarantini et al. 2015b); they are, however, never found in the nucleus. Reports to the contrary always refer to dye-labelled or otherwise modified silicon dioxide. Such materials, however, are not permitted for use as a food additive. These results cannot be read across to E 551, and it is not appropriate to conclude from them that unlabelled and unmodified silica particles would translocate in the cell nucleus. Several researchers have also relied on dye-labelled or modified silicon dioxide particles to trace the fate of silica in the body; these particles are, however, different from E 551 with regard to their physico-chemical properties (in particular different particle sizes, surface area, porosities, and stabilities), and the influence of dyes on the biodistribution, stability, and toxicity of silica particles is not sufficiently studied. Data generated from studies with these engineered materials cannot therefore be read across to E 551. Often results from intravenous studies are employed to derive biodistribution of SAS after oral exposure, e.g. by van Kesteren et al. (2015). Patterns of distribution can, however, be expected to be different, because of the different mode of application (local bolus directly into the intravenous compartment versus a slow absorption pattern by the large area of the intestinal tract after oral exposure), resulting also in different surface modifications (different corona formation) according to the route of entry (Inlivetox 2012). As already suggested 
earlier (NANOGENOTOX 2013), it can be concluded that the systemic availability of silica particles is low after oral exposure. The dissolved form might be absorbed by the intestinal tract.

\section{Toxicity}

Core areas defined by EFSA for the assessment of food additive toxicity include genotoxicity, subchronic and chronic toxicity, carcinogenicity, and reproductive and developmental toxicity as well as neurotoxicity, immunotoxicity, and endocrine-mediated effects (EFSA 2012). These areas are therefore addressed in the following sections.

\section{Genotoxicity}

Food-grade silicon dioxide was neither mutagenic nor genotoxic in standard in vitro test systems (Ames, HPRT, mouse lymphoma, and chromosome aberration studies) (CEFIC 2012a, b; ECETOC 2006). In vitro micronuclei tests were negative in human lymphocytes and BEAS2B cells, inconclusive in undifferentiated Caco- 2 cells, and positive in some lung-derived cells at cytotoxic concentrations (NANOGENOTOX 2013; Tarantini et al. 2015b; Tavares et al. 2014; Zijno et al. 2016). The findings of in vitro indicator tests were negative for pyrogenic and hydrated silica under non-cytotoxic conditions (cf. Table 3 for details).

Standard oral in vivo genotoxicity tests were all negative (bone marrow micronucleus test, chromosome aberration test (NANOGENOTOX 2013; Tarantini et al. 2015a). Also, the pig-a test and the in vivo comet assay were negative (Guichard et al. 2015; NANOGENOTOX 2013; NANoREG 2015; Tarantini et al. 2015a). The organs/tissues studied in the comet assay were liver, kidney, blood, bone marrow, stomach, duodenum, and colon. It is noted that "significant increased DNA damage" in the comet assay was reported in bone marrow and spleen of male rats, and in ovary cells, all without a dose-response relationship, after daily gavage exposure for 45 days within a 90-day study with pyrogenic food-grade SAS. The low doses employed (maximum dose $50 \mathrm{mg} / \mathrm{kg}$ bw/day) which are below the normal range of rat diet silicon content (see, for example, Jugdaohsingh et al. 2015; van der Zande et al. 2014), the lack of a dose-response, and the known variability in comet results indicate that these observations are within the normal physiological range. No effects were found in testes, liver, kidney, intestines, and colon (Fessard et al. 2016; NANoREG 2015). Additionally, a non -standard colon micronucleus test was performed following repeated oral administration of precipitated and pyrogenic SAS on three consecutive days. No induction of micronuclei was found with precipitated SAS, but a slight increase in borderline statistical significance was noted in colon samples of rats treated with the lowest dose $(5 \mathrm{mg} / \mathrm{kg}$ bw/ day) of pyrogenic SAS (NANOGENOTOX 2013; Tarantini et al. 2015a). The preliminary genotoxicity data from the ongoing 90-day study in rats do, however, not show any genotoxic effects on the gastrointestinal tract (NANoREG 2015); in particular, no micronuclei were found in colon samples (Fessard et al. 2016) again indicating that the observations are within the normal physiological range and not substance related. The very low genotoxic potential is also evidences by studies employing the intravenous route, when genotoxicity (micronuclei) was only found at doses exceeding the maximum tolerated dose (MTD) level (Downs et al. 2012; NANOGENOTOX 2013).

The available genotoxicity studies are summarised in Table 3 (in vitro studies) and Table 4 (in vivo studies).

\section{Subchronic and chronic toxicity}

The available oral studies include 28-day gavage and feeding studies with pyrogenic silica, a 28-day gavage study with precipitated silica (CEFIC 2011; van der Zande et al. 2014), an old 90-day feeding study with pyrogenic silica (ECETOC 2006), and 84- and 90-day feeding studies with precipitated silica (ECETOC 2006; van der Zande et al. 2014). A low-dose 90-day gavage study with pyrogenic silica (NM-203) is still ongoing (NANoREG 2015). Details on the older studies have been summarised in the documents by the IARC (IARC 1997), the OECD (OECD 2004), the ECETOC (ECETOC 2006), the EFSA (EFSA 2004, 2009) and been published within the OECD Programme on Nanomaterials. ${ }^{1}$

An overview of the available oral studies and their main results is presented in Table 5. Because colloidal silica is chemically identical apart from stabilisers and possibly additives, results with colloidal silica are also included in the table, although it is not permitted to be used as E 551.

In the 28-day rat studies, NOAELs of $1000 \mathrm{mg} / \mathrm{kg}$ bw/ day or above were determined, with no specific target organs identified (CEFIC 2011; van der Zande et al. 2014). In an extended study according to OECD TG 407 (CEFIC 2011), the measurements of the spontaneous locomotor activity and the functional observational battery showed no influence of the treatment up to and including the highest

\footnotetext{
1 http://www.oecd.org/chemicalsafety/nanosafety/testing-programme-manufactured-nanomaterials.htm, accessed May 27, 2016.
} 


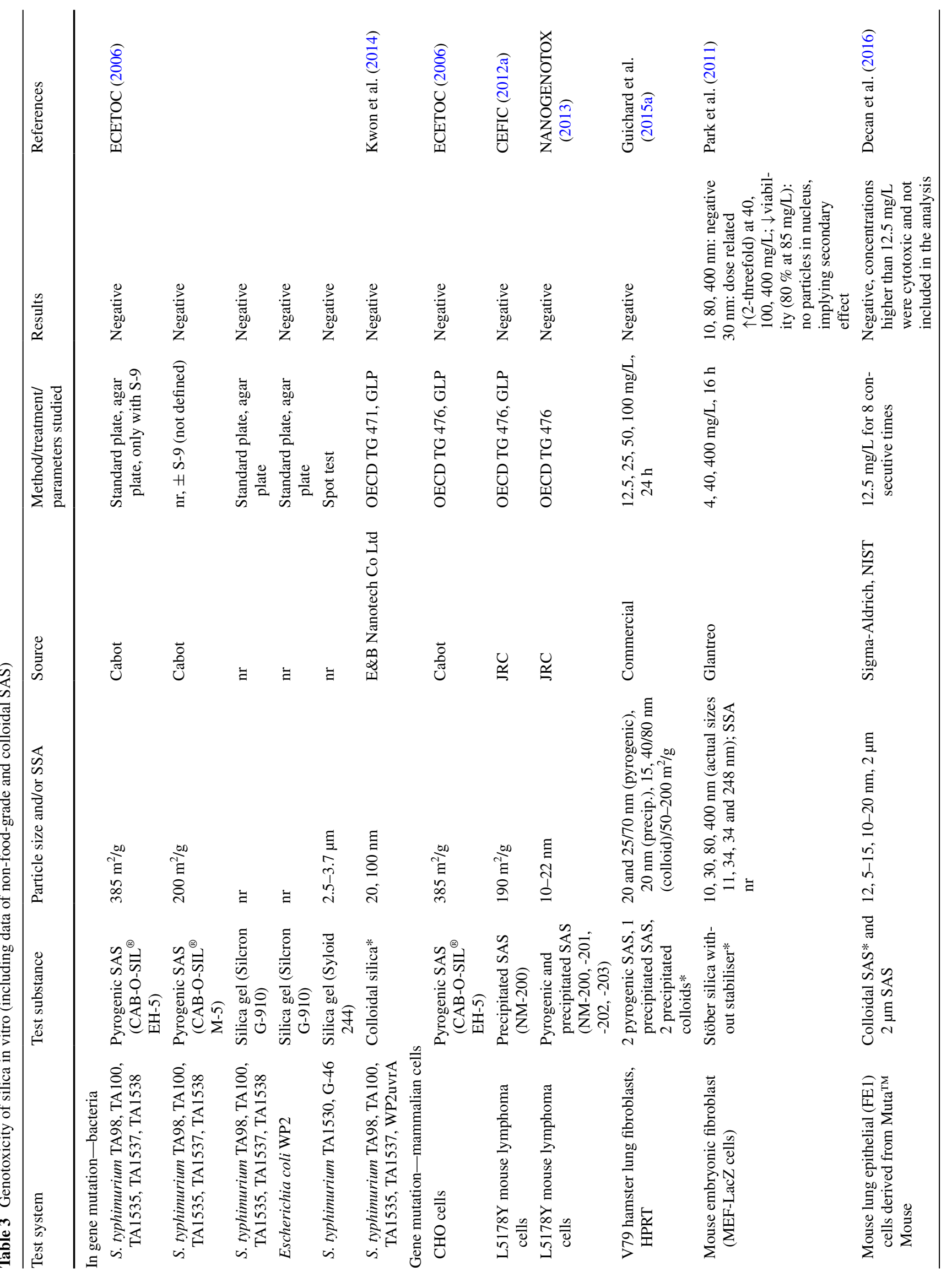




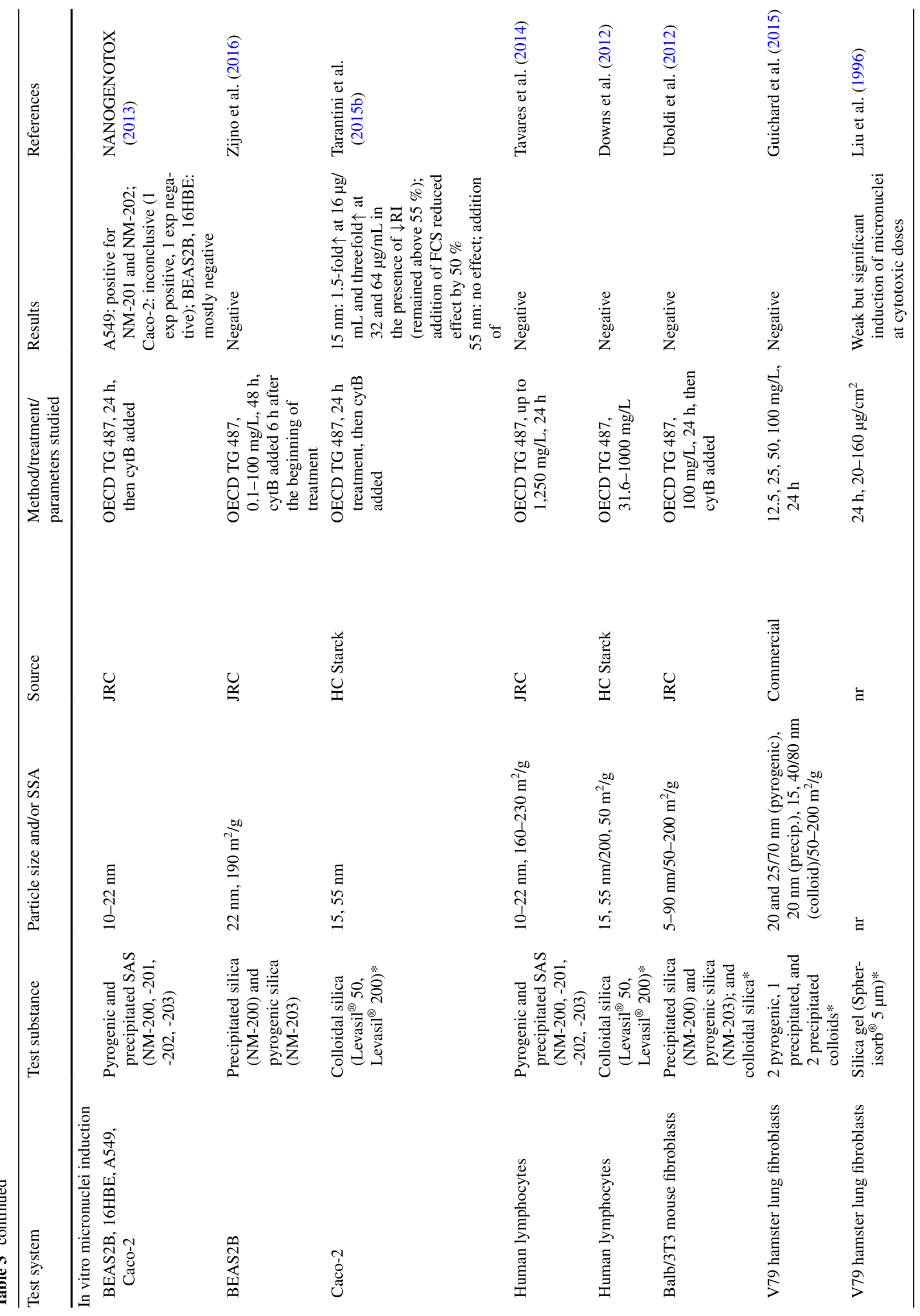




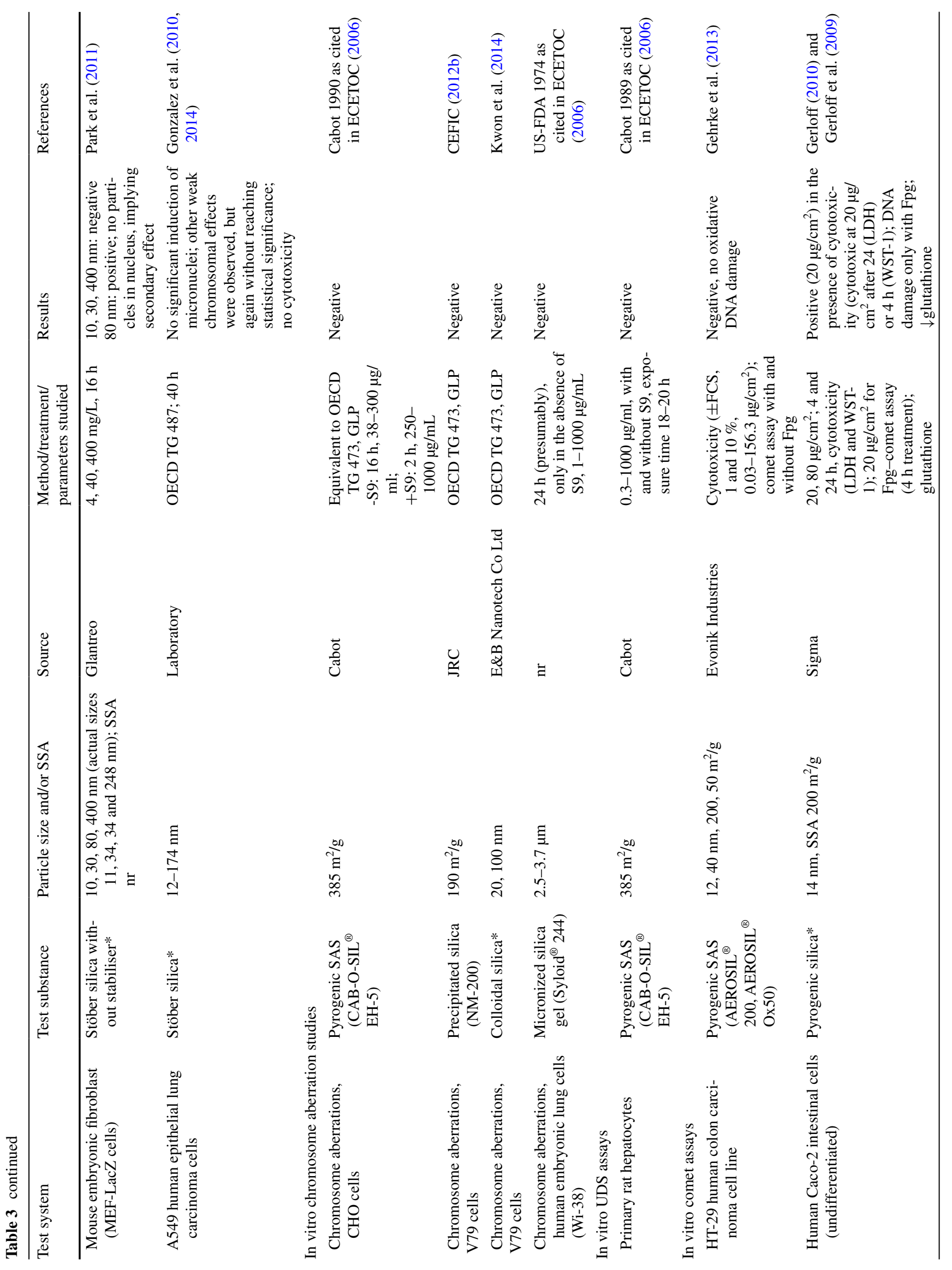




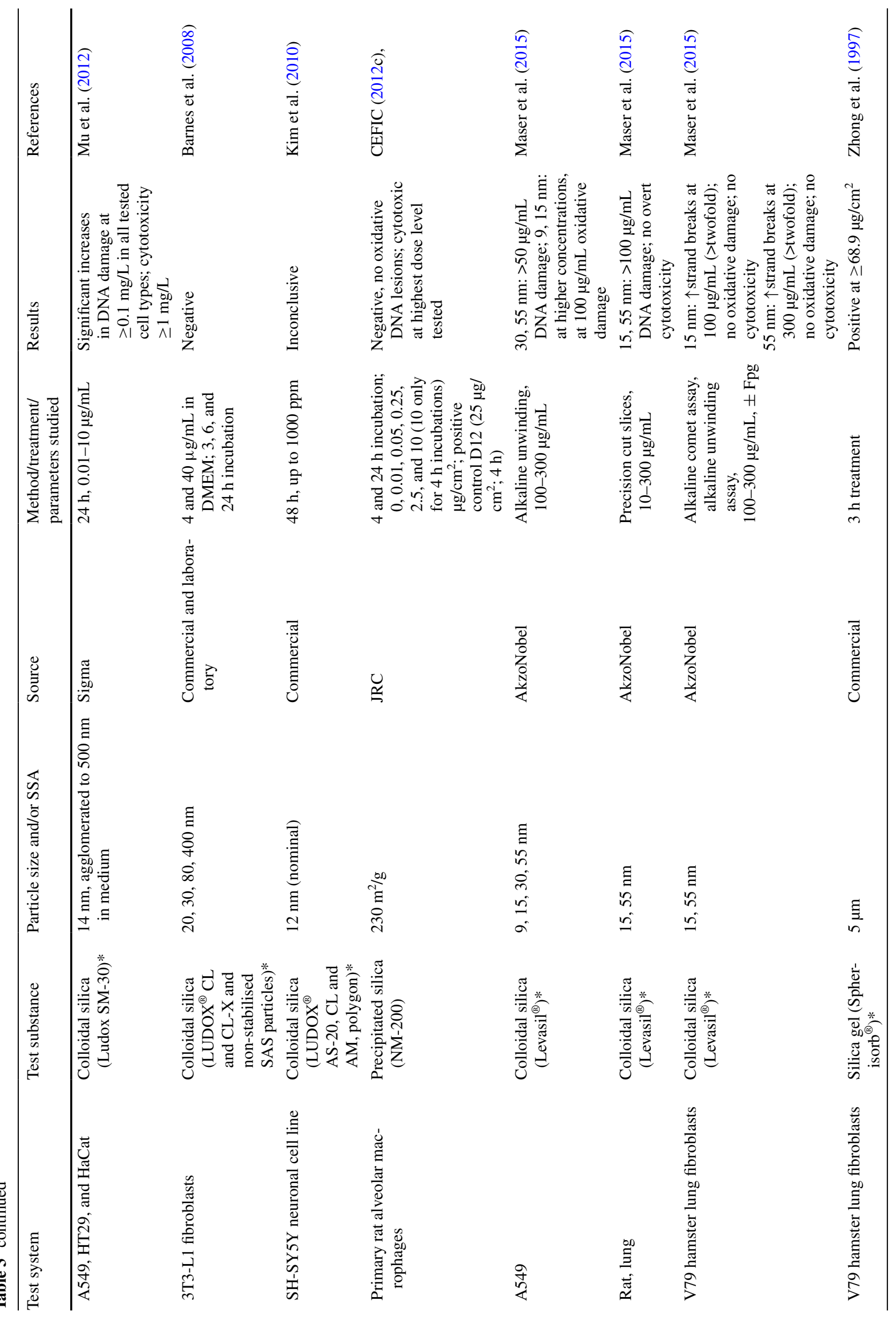




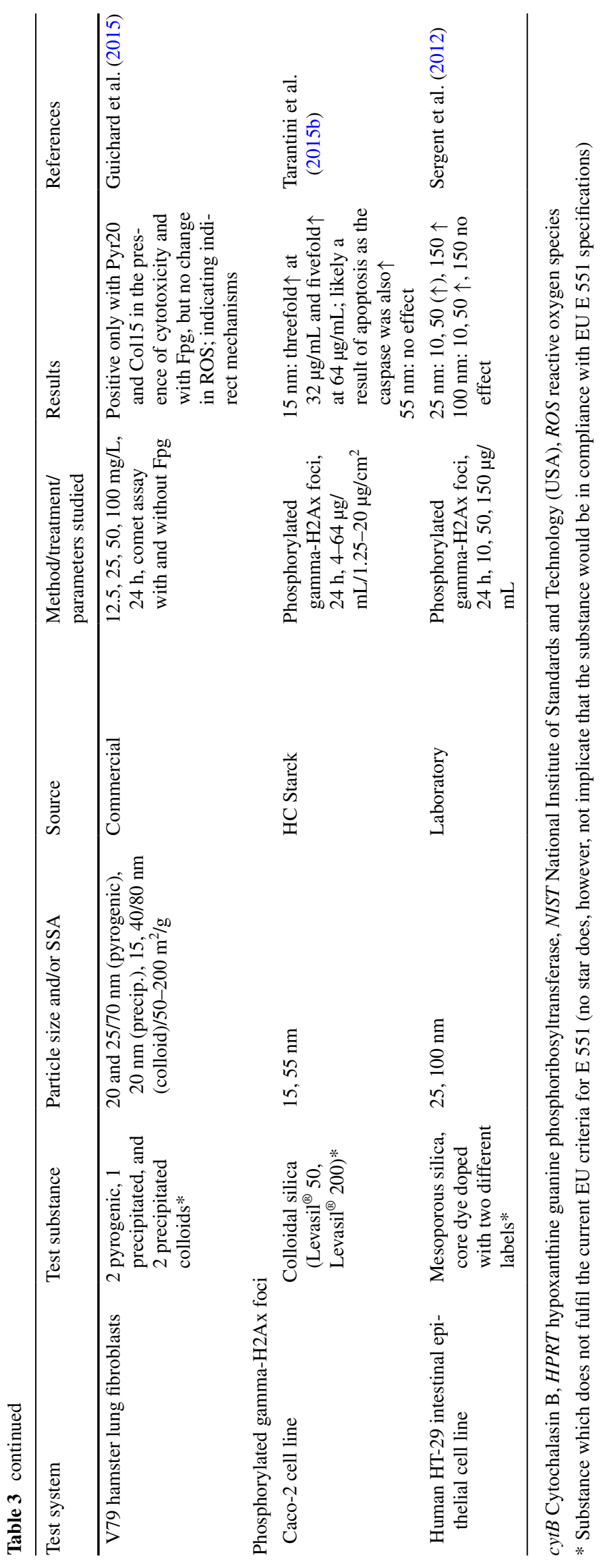




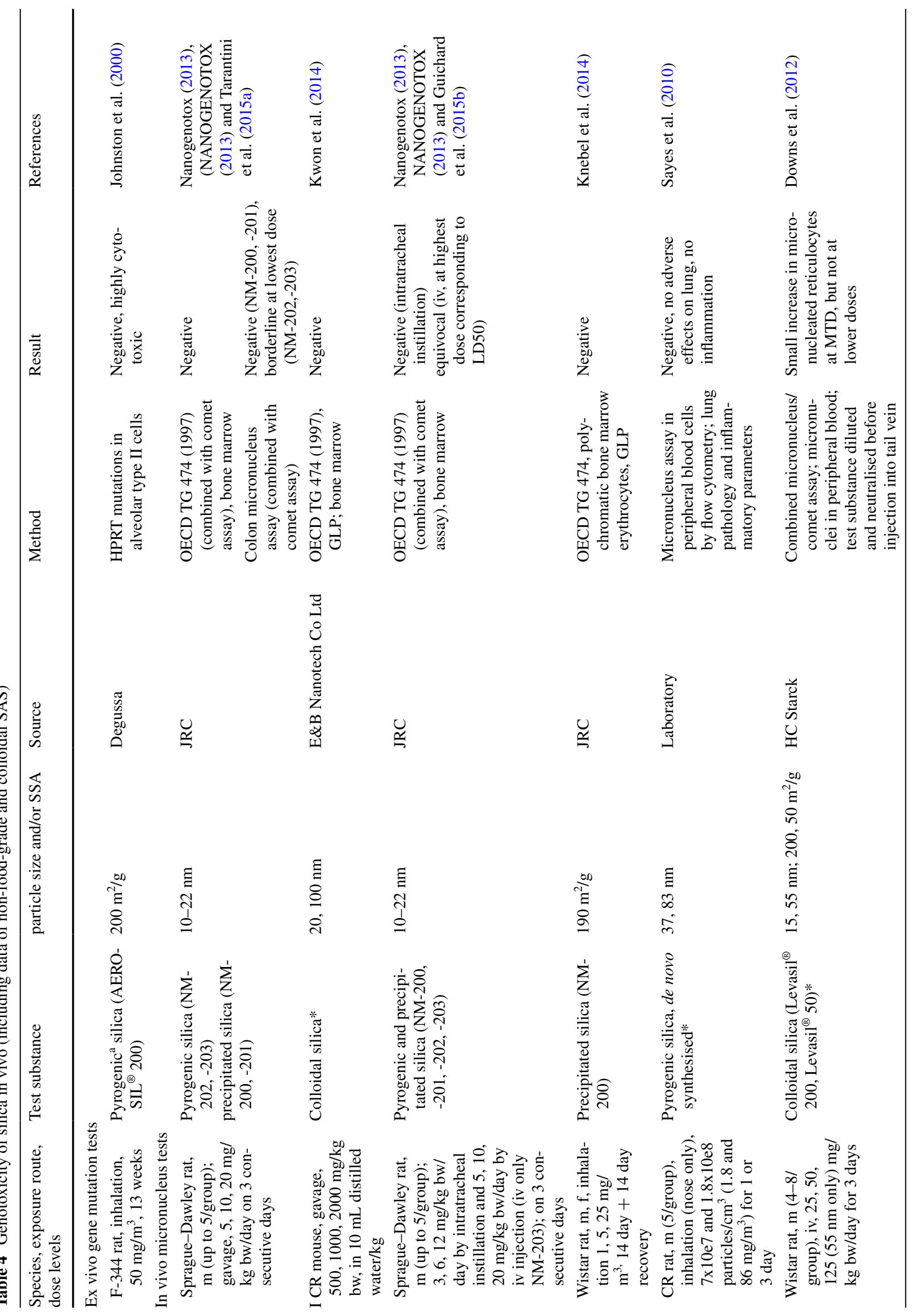




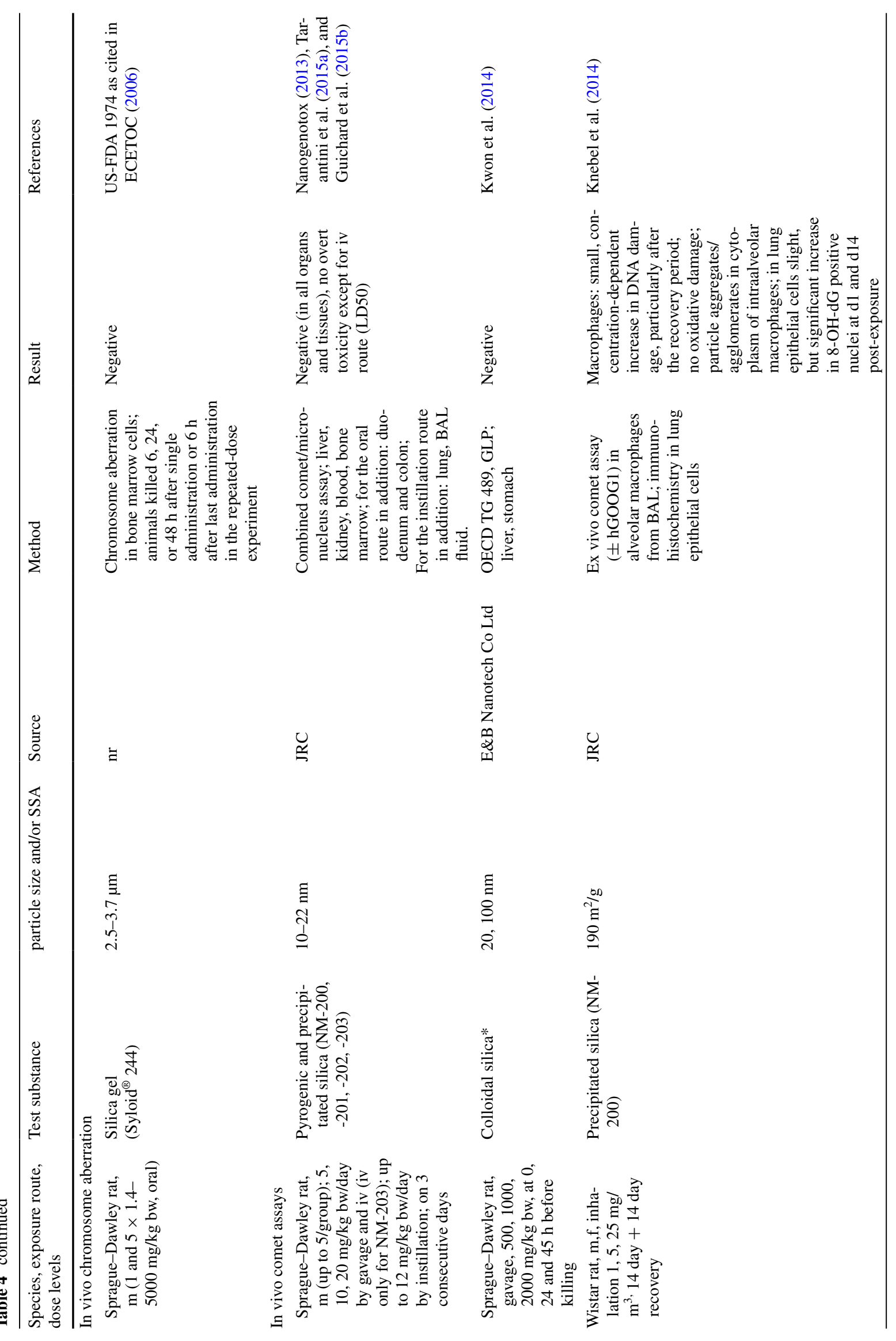




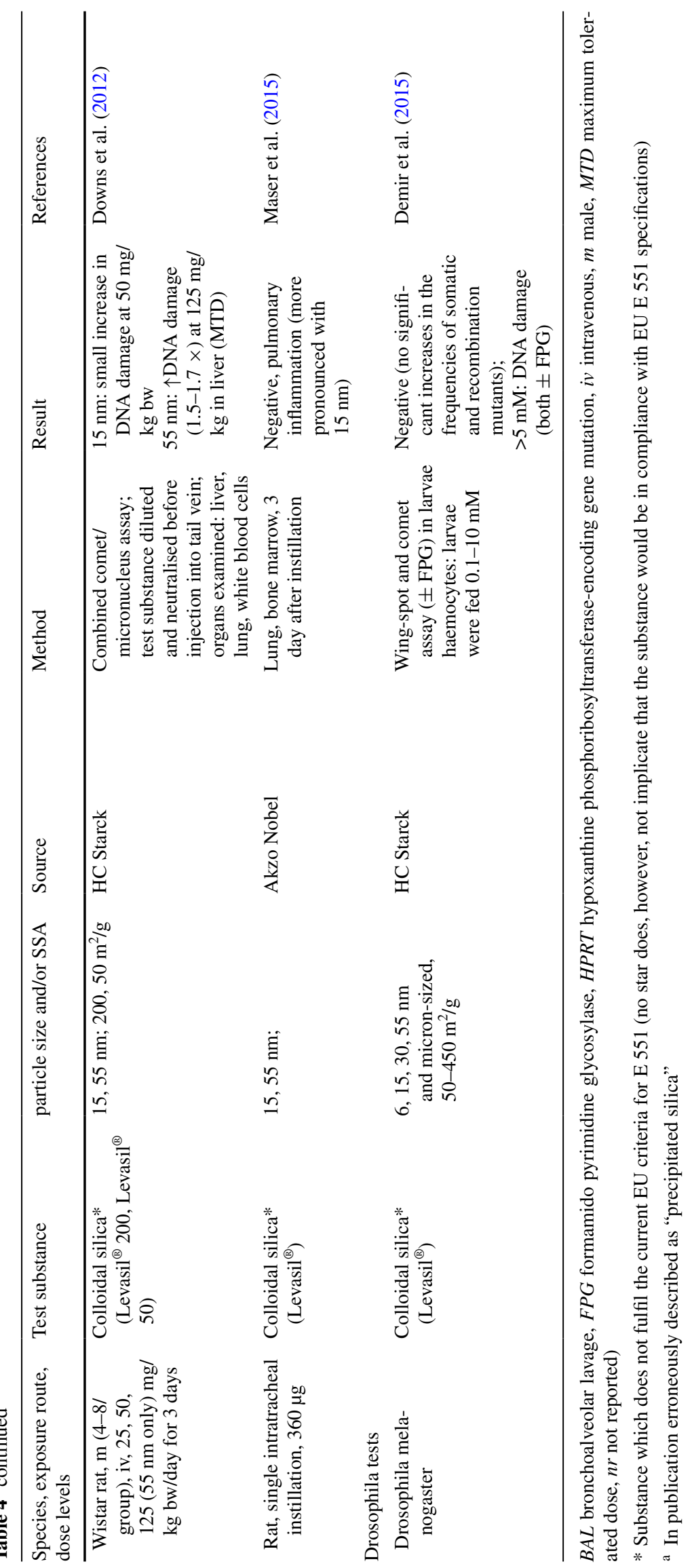


tested dose of $1000 \mathrm{mg} / \mathrm{kg}$ bw/day (it is noted that only male animals were used in this study).

Similarly, the NOAELs in the 90-day rat studies were also at $1000 \mathrm{mg} / \mathrm{kg}$ bw/day or above with no specific target organs identified (ECETOC 2006; van der Zande et al. 2014). Only in one single rat study, in which two pyrogenic silica products (designated NM-202 and "SAS") were studied in parallel, mild liver fibrosis was reported after oral exposure to $1000 \mathrm{mg} \mathrm{NM}-202 / \mathrm{kg}$ bw/day, but not after dosing SAS at $2500 \mathrm{mg} / \mathrm{kg}$ bw/day. In this study (van der Zande et al. 2014), the occurrence-but not the severityof periportal liver fibrosis was reported to be significantly increased ( $p=0.021$ when compared with the control animals). Fibrosis is, however, not visible on the histological images presented in the publication [Fig. 5, F/G; referred to as showing fibrosis by (van der Zande et al. 2014)]. The small amount of connective fibrous tissue represents the normal anatomical situation of periportal fields where bile ducts, arteries, and veins are located within a small amount of fibrous tissue. Hence, the histopathological diagnosis of periportal fibrosis in this study has to be questioned (K. Weber, AnaPath GmbH, personal communication, July 2016). Liver silicon concentrations, liver enzymes, and biochemical markers were unaffected, and "the number of lymphocytic cells and thereby also the number of inflammatory granulomatous foci (the average number of cells in each of the foci) remained unchanged after 28 , and 84-days" was unchanged, as evidenced by quantitative histological assessment of livers (van der Zande et al. 2014). There was therefore no evidence found for Kupffer cell activation (which might induce liver re-modelling), or inflammatory granuloma formation as a key event for the induction of liver fibrosis. Results from in vitro studies show that liver cells are not very sensitive towards SAS, and that relevant toxicity is only caused when incubated with Kupffer cells (Chen et al. 2013). Taken together, the lack of significant exposure after oral intake and the absence of inflammation, resident or peripheral macrophage stimulation and granuloma formation in the liver, clearly demonstrate that there is no plausible mechanism for the induction of liver fibrosis by oral intake of E 551 .

\section{Carcinogenicity}

The carcinogenic potential of silica gel (Syloid $\left.{ }^{\circledR} 244\right)$ was investigated in an oral study in $\mathrm{B} 6 \mathrm{C} 3 \mathrm{~F} 1$ mice and $\mathrm{F} 344$ rats (20/sex/group/species) after dietary administration at 0 , $1.25,2.5$, and $5 \%$ for at least 21 and 24 months, respectively. These concentrations correspond to dose levels of approximately $0,1800,3500$, and $7000 \mathrm{mg} / \mathrm{kg}$ bw/day for mice and $0,625,1250$, and $2500 \mathrm{mg} / \mathrm{kg}$ bw/day for rats. The administration of silica gel was well tolerated. There were no biologically or toxicologically significant changes, and silica gel was therefore considered to be devoid of toxic or carcinogenic potential (Takizawa et al. 1988).

\section{Reproductive and developmental toxicity}

No adverse effects on reproduction or development were found in old and limited studies with silica gel as reviewed by the EFSA $(2004,2009)$. In a dominant lethal test performed with silica gel [US-FDA 1974, as cited by ECETOC (2006)], no effects of treatment (up to $5 \times 5000 \mathrm{mg} /$ $\mathrm{kg}$ bw, oral) were found on fertility index, total number of implantations of corpora lutea, pre-implantation losses, and dead implants. Results from several oral repeated-dose toxicity studies did not indicate any adverse health effects including the highest tested dose levels.

After intravenous dosing of mice with colloidal 70-nm silica particles, placental dysfunction, foetal resorption, and growth retardation were reported $(0.2,0.4$ and $0.8 \mathrm{mg} /$ mouse on gestational day (GD)16 and GD17) (Yamashita et al. 2011). The effects could be prevented by a combined treatment with heparin, and the activation of the complement system was therefore assumed as a potential mecha-

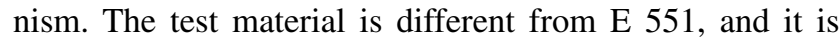
unlikely that after oral exposure, silica particles would be present in blood and reproductive organs at similarly high levels as achieved by intravenous injection. These findings are therefore not relevant for the assessment of E 551 . Modern guidelines studies employing the oral route have not shown any adverse effects of food-grade silicon dioxide on the foetus (see below).

In a recent embryonic stem cell test (EST) performed within the EU FP7-funded MARINA project, precipitated and pyrogenic silicon dioxide as used in food additives (NM-200 and NM-203) was classified as "non-embryotoxic" (Farcal et al. 2015). A study reporting inhibition of embryonic stem (ES) cell differentiation after exposing the D3 murine ES cell line to spherical laboratory-synthesised amorphous silica nanoparticles (Park et al. 2009) is not considered relevant, as such material is not used in food additives. In vitro studies with human placental models, performed within the EU FP7 project NanoTest, were inconclusive, and, as it seems performed with fluorescent dye-labelled material which is different from E 551 (Dusinska and Tran 2015; Poulsen et al. 2015).

Within the Cefic LRI testing programme, precipitated synthetic amorphous silica has recently been tested in GLP and guideline studies for its potential effects on reproduction and development. These studies are summarised in the following sections.

A GLP oral two-generation reproductive toxicity study was recently performed in the Wistar rat according 


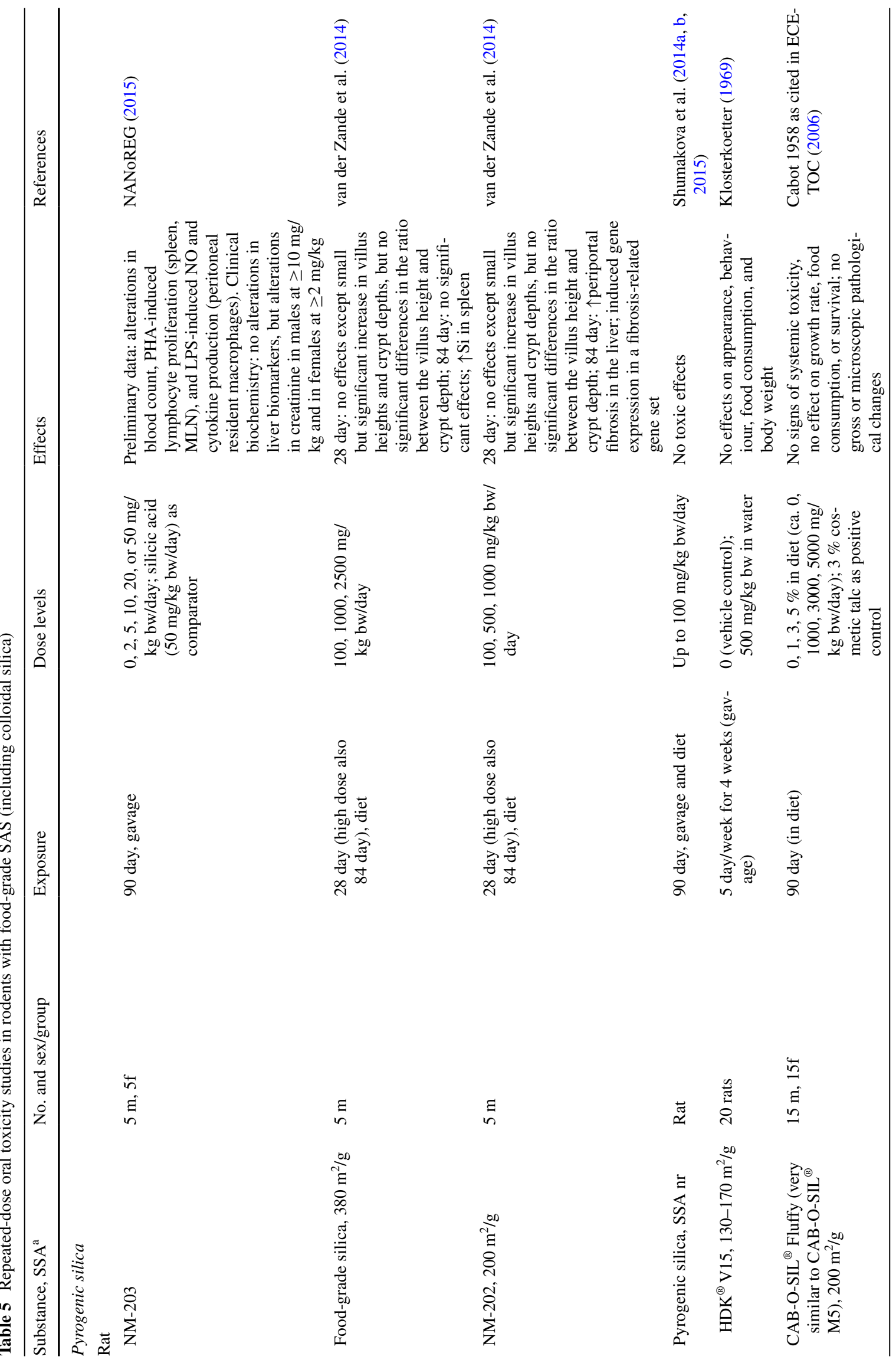




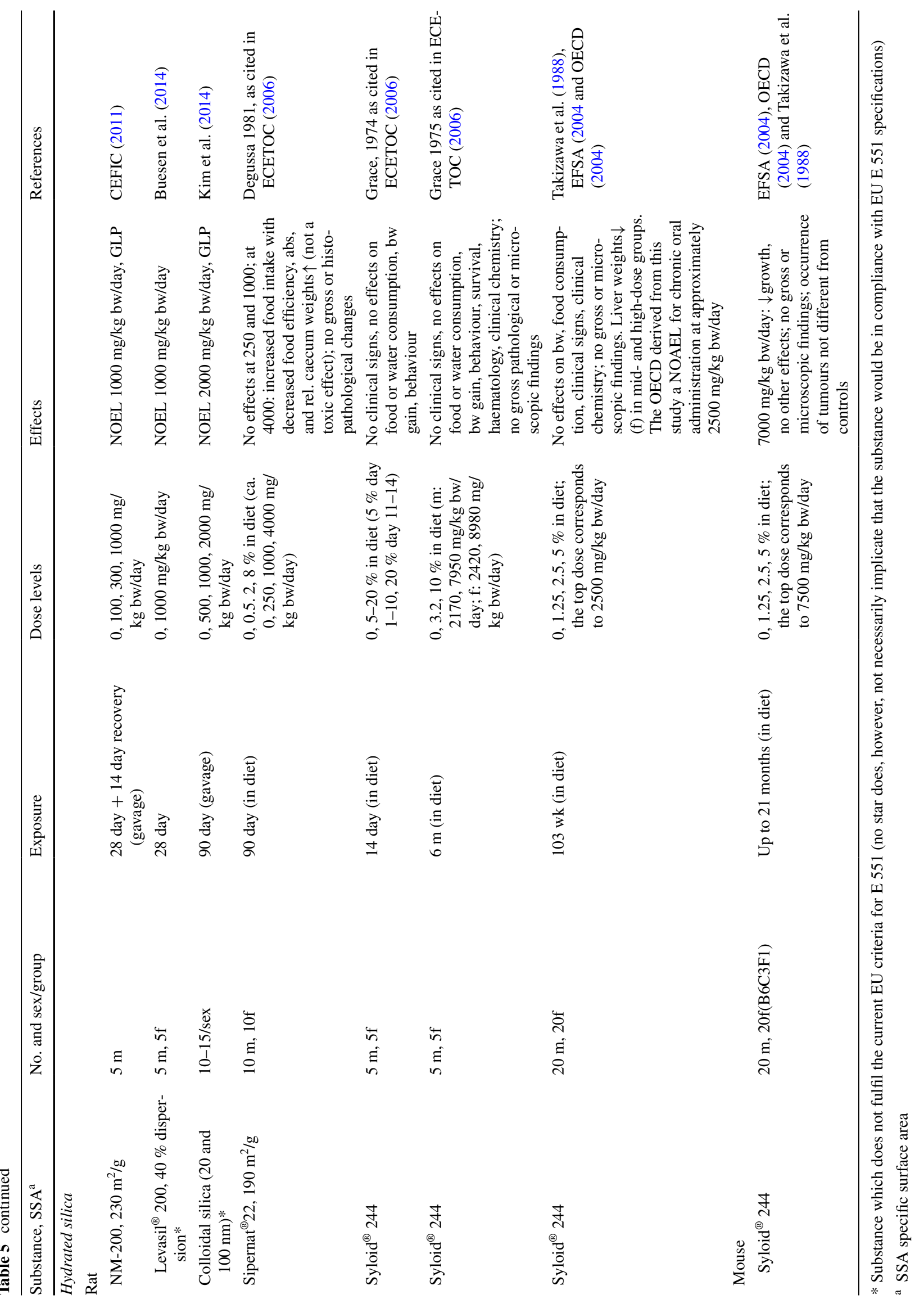


to OECD guideline 416 (Wolterbeek et al. 2015). The administration by gavage of precipitated synthetic amorphous silica (NM-200, purity $96.5 \%$ ) at doses up to $1000 \mathrm{mg} / \mathrm{kg}$ bw/day had no adverse effects on the reproductive performance of rats or on the growth and development of the offspring into adulthood for two consecutive generations. The NOAEL was $1000 \mathrm{mg} / \mathrm{kg}$ bw/day. The mean hydrodynamic diameter of the silica particles in the $10 \mathrm{~g} / \mathrm{L}$ study samples (dispersion in $0.5 \%$ aqueous methylhydroxypropyl cellulose) varied between 1076 and $1664 \mathrm{~nm}$ and for the $30 \mathrm{~g} / \mathrm{L}$ study samples between 876 and $1216 \mathrm{~nm}$, respectively. The measured size of the $100 \mathrm{~g} / \mathrm{L}$ study samples appeared to be the smallest (409$703 \mathrm{~nm}$ ), but due to the high concentration of the particles in the samples, the particles sedimented and aggregated. The animals received the test substance during a premating period of 10 weeks, during mating, gestation and lactation until sacrifice. Dams were allowed to raise one litter. At the end of the lactation period, pups were weaned and selected for the next generation. F0- and F1-dams were sacrificed at or shortly after weaning, and F0- and F1-males after mating. F1-pups were dosed by gavage at the same dose levels as their parents from post-natal day 21 until sacrifice. Reproductive parameters (including oestrus cycle, evaluation, and sperm analysis) and developmental parameters (including sexual maturation) were measured. At sacrifice, reproductive organs and tissues were sampled for histopathological analysis. In both generations, no treatment-related effects were observed on body weights, body weight changes, and food consumption. In both generations, no treatment-related effects were observed on oestrus cycle parameters of the female animals and on sperm parameters of the male animals. In both generations, no effects of the test item were observed on mating, female fecundity, male- and female fertility, and gestation indices. Pre-coital time, duration of gestation, and the incidence of dams with stillborn pups or implantation loss were not affected. No test substancerelated adverse effects were observed on the mean number of pups delivered, the incidences of live born- and stillborn pups, the number of pups lost during the lactation period, the sex ratio, clinical observations, nor necropsy findings. In both generations, there were no effects on pup weights and pup weight changes. No statistically significant differences were found amongst the various groups in timing of testes descent, preputial separation, and vaginal opening. There were no gross pathological findings in the stillborn pups, pups that died during lactation, and in pups necropsied at post-natal day 21. Organ weights of pups and of parents of both generations were not affected. There were also no gross or histopathological changes in the F0- and F1-generation animals.
In a GLP study on rats in compliance with OECD TG 414 , orally administered precipitated silica (NM-200) had no adverse effects on development; the NOEL was at $1000 \mathrm{mg} / \mathrm{kg}$ bw/day, the highest dose tested (Hofmann et al. 2015; Schneider et al. 2011). The test substance, dispersed in water with $10 \%$ foetal bovine serum, was administered at doses of $0,100,300$, and $1000 \mathrm{mg} / \mathrm{kg}$ bw/ day from GD 6 through GD 19 by oral gavage. On GD 20, all females were assessed by gross pathology, including weight determinations of the uterus and the placentas. The corpora lutea were counted, and the number and distribution of implants (resorptions, live and dead foetuses) were determined. The foetuses were removed from the uterus, their sex determined, weighed, and investigated for external findings. Half of the foetuses of each litter were examined for soft tissue findings and the remaining foetuses for skeletal (and cartilage) findings.

No differences were found between the treatment groups and controls with regard to clinical observations, body weights, and food consumption of the dams. No effects were observed on number of corpora lutea, implants, preand post-implantation losses, or number and viability of offspring. External, soft tissue and skeletal examination showed no test substance-related abnormalities. The No Observed Effect Level (NOEL) for maternal and developmental toxicity was therefore derived at $1000 \mathrm{mg} / \mathrm{kg} \mathrm{bw} /$ day, the highest dose tested.

The results of this modern guideline study are in line with earlier findings in limited prenatal developmental toxicity studies performed with silica gel (Syloid $\left.{ }^{\circledR} 244\right)$ by the oral route in rats, mice, hamsters, and rabbits. The NOELs for maternal and developmental toxicity in these studies were at $1340-1600 \mathrm{mg} / \mathrm{kg}$ bw/day, the highest doses tested (US-FDA 1973. as cited in ECETOC 2006).

\section{Neurotoxicity, immunotoxicity, endocrine-mediated effects}

The available information from repeated-dose, developmental, and reproductive toxicity studies does not indicate any adverse effects on the nervous, immune, or endocrine systems. Dedicated studies for neurotoxic, immunotoxic, or endocrine-mediated effects were therefore not performed. A functional observation battery (FOB) was integrated in the 28-day repeated-dose toxicity study (CEFIC 2011), and lymphoid tissue and immunological parameters were investigated in 28- and 84-day studies (van der Zande et al. 2014). In none of these investigations, was any indication of neurological or immunological effects found.

With two food-grade pyrogenic silicon dioxide products (NM-203 and SAS), no effects were found on antibody 
levels in blood (IgG and IgM), or on cytokine levels produced by proliferating $\mathrm{T}$ and $\mathrm{B}$ cells, that were isolated from spleen and mesenteric lymph nodes. Proliferation of the isolated T and B cells and the activity of NK cells isolated from spleen were also examined after 28 days of exposure, but remained unaffected. Immunotoxicity parameters were also studied in vitro and in vivo within the 90-day gavage study performed with NM-203 in the low-dose range (Di Felice et al. 2016; NANoREG 2015). The parameters studied in vitro included inflammatory and functional endpoints in the murine macrophage cell line RAW264.7, apoptosis/necrosis, cytokine secretion, and NO production. No significant effects were found in vitro, but an "impaired lymphocyte response to mitogen associated with reduced numbers of circulating white blood cells, and enhanced inflammatory response by peritoneal macrophages" were reported (Maranghi et al. 2016). In the absence of any other biochemical changes indicating inflammatory processes or adverse effects, these findings and the reported statistically significant increase in the incidence of intralobular lymphoid infiltration in livers of females are not considered to have toxicological relevance. Since the silica doses employed in this study are within the normal silica content range of usual laboratory rat diets*, it is very unlikely that an adverse effect would be caused by the doses employed. [*up to $5000 \mu \mathrm{g} \mathrm{Si} / \mathrm{g}$ food ((De Jong 2012), resulting in up to $400 \mathrm{mg} \mathrm{Si} / \mathrm{kg}$ bw assuming a food intake of $20 \mathrm{~g} /$ day for a $250 \mathrm{~g}$ rat.].

\section{Information from in vitro studies}

Many have investigated the in vitro effects of silica particles in a wide variety of cell types. While previously cells of the respiratory tract were the focus of the studies, more recently also cells relevant, or potentially relevant, for the oral exposure route have been investigated. E 551 exerts its function as anti-caking agent mainly by covering the surface of host powders and thus acting as a spacer, and through its water adsorption capacity. Similarly, SAS particles may adsorb to cellular surfaces and proteins and may thus affect biological membrane structures and integrity. The in vitro results vary with the cell type and the extent of direct contact with silica particles. Except for red blood cells, macrophages were shown to be the most sensitive cell type after in vitro exposure to pyrogenic and precipitated silica. Alveolar macrophages were more sensitive than peritoneal macrophages (Di Cristo et al. 2016; Farcal et al. 2015; Fruijtier-Pölloth 2012). This is consistent with the physiological function of macrophages to clear particulate matter from the body. In vitro studies in cell types with relevance to the oral exposure route are summarised in Table 6.

\section{Discussion}

The smallest constituent particles in E 551 are the aggregates, in which no primary particles are discernible. In order to exert its technological function as anti-caking agent in foods, E 551 must be present in sizes greater than $100 \mathrm{~nm}$, and nanosized particles are therefore actually not desired. The results of aggregate size measurements are much influenced by sample preparation, including dispersion and dilution methods, and show volume weighted external diameters generally greater than $100 \mathrm{~nm}$ when using several different particle sizing techniques (data on file). This is in agreement with analytical results from the JRC showing E 551 aggregate sizes of greater than $100 \mathrm{~nm}$ when measured by dynamic light scattering (DLS) after applying ultrasonic dispersion at around 3000 Joule and filtering off larger particles (Barahona et al. 2016). Number weighted particle size distributions are currently not measurable with standardised methods, and estimates suffer from the assumption that SAS aggregates are spherical particles, which is inaccurate in the case of E 551. From the results of a recent study within the EU FP7-funded NanoDefine project (http://www.nanodefine.eu/) using several available particle sizing techniques, it has been concluded that "...the determination of the smallest external dimension remains challenging (if possible at all) for several classes of morphology, e.g., for three-dimensional aggregates..." (Babick et al. 2016). In this study, a stabilised suspension of fumed silica particles (colloidal silica) was used, which must not to be confused with E 551 .

After oral intake, it might be possible that $\mathrm{E} 551$ disintegrates during its passage through the intestinal tract. Available evidence, however, shows that there is no release of small particles in the acidic environment of the stomach. In more distal parts of the intestines, the more alkaline $\mathrm{pH}$ environment may cause some dissolution and formation of orthosilicic acid. As shown by van der Zande (van der Zande et al. 2014), silicon dioxide particles in the nanosize range (defined by the study authors to be below $200 \mathrm{~nm}$ ) are found in the colon of non-E 551-exposed animals. The finding is also in agreement with biodurability studies performed in Caco-2 medium by the JRC (JRC 2013).

The overall evidence also shows that there is no indication that oral intake of E 551 may lead to liver toxicity. Studies cited in literature that show liver toxicity after amorphous silica exposure either relate to dye-labelled material, to biogenic material, or to exposures by the intravenous route. Studies with dye-labelled material cannot be read across to $\mathrm{E} 551$, since the tested materials are different from E 551, and the influence of the dye on stability, distribution, and toxicity are not sufficiently known. Liver fibrosis could be induced after intravenous injection 
of amorphous silica particles (though colloidal, and not E 551 ) at doses of $50 \mathrm{mg} / \mathrm{kg}$ bw or even higher. Such exposures have been shown to activate Kupffer cells with an increase in inflammatory markers and subtle biochemical changes, including a slight increase in AST in mice, minor to moderate histopathological changes, and inflammatory liver granulomas in rats (Chen et al. 2013; Downs et al. 2012). Liver granulomas containing resident (Kupffer cells) and recruited macrophages and lymphocytes were also found after intravenous injection of pyrogenic SAS at $7 \mathrm{mg} / \mathrm{kg}$, but there were no changes in biochemical serum marker. This finding was attributed to particle clearance mechanisms including uptake by macrophages and lysosomal degradation (Ivanov et al. 2012). However, systemic exposure levels, and hence also liver tissue exposure levels, that can be achieved by intravenous bolus injection cannot be reached after oral intake or gavage. There is therefore no basis for the assumption of a macrophage-induced liver remodelling and fibrosis after oral exposure, a pathway that theoretically might be possible, see, for example, (Ju and Tacke 2016).

In none of the several other available studies, including an ongoing 90-day study with pyrogenic SAS in the low-dose range (NANoREG 2015), was any sign of liver fibrosis seen, nor any biochemical changes relating to liver toxicity found. To derive effect levels or calculating benchmark doses for E 551 based on the reported liver fibrosis in a single study (Jacobs et al. 2015) is therefore not justified.

In none of the available in vivo studies was there any adverse local effect on the gastrointestinal tract reported. Small but significant increase in villus heights and crypt depths in the jejunum, but no significant differences in the ratio between the villus height and crypt depth were found by van der Zande et al. (van der Zande et al. 2014). According to the study authors, long villi and a high villus:crypt ratio indicate a highly differentiated and active tissue. Gene set enrichment analysis on microarray data of jejunal epithelial samples from either the 28 or 84 days of exposure to both SAS and NM-202 did not show differences in gene expression profiles between the treatment groups and the controls. This finding is therefore not considered to be adverse.

It has previously been hypothesised that accumulation of non-degradable particles in human Peyer's patch macrophages could exacerbate inflammation in Crohn's disease (CD), but this could not be confirmed in human studies (Lomer et al. 2004). In work published in the form of a doctoral thesis, a silica-enriched diet containing $0.1 \%$ SAS (which was not a product with the specifications of E 551) exacerbated the symptoms of irritable bowel disease (IBD) and enhanced mucosal inflammation in murine models of colitis (HA-VILLIN, DSS-induced acute and chronic colitis). SAS had no effects in healthy mice used as controls.
Oxidative DNA damage was even decreased in the colon tissue of colitis-induced mice and of healthy mice treated with the SAS-enriched diet when compared to controls (Winter 2010). An upregulation of MHC-II, CD80, and CD86 on dendritic cells (DC) was found in vitro, and proinflammatory IL-beta was increased in endotoxin-activated DCs (Winter et al. 2011). In view of the absence in animal studies of any effects indicating immunotoxicity, and given that silicon dioxide particles are amongst the most abundant substances in the environment, including vegetable foods and the fact that the mucosa of the gastrointestinal tract is therefore continuously exposed, it is unlikely that gut-associated lymphoid tissue and immunity could be adversely affected by the presence of silicon dioxide as used for E 551.

In vitro, neither pyrogenic nor precipitated silica affected the cell barrier integrity in Caco-2 intestinal cells, even after long-term exposure (7-21 days); with both pyrogenic and precipitated silica cytotoxic and cytostatic effects were registered only at very high concentrations $(\geq 100 \mathrm{mg} / \mathrm{L}$ in human gastric epithelial cells (GES-1) and Caco-2 cells) (Contado et al. 2016; Farcal et al. 2015; Yang et al. 2014). In liver cells, GSH depletion and oxidative stress have been found only at very high test concentrations ( $\geq 200 \mathrm{mg} / \mathrm{L})$, or long incubation times ( $25 \mathrm{mg} / \mathrm{L}$ for $72 \mathrm{~h}$ ); aspartate aminotransferase in buffalo rat liver cells incubated with supernatant from $\mathrm{SiO}_{2}$-stimulated Kupffer cells (resident hepatic macrophages) was only increased at $\geq 400 \mathrm{mg} \mathrm{SiO} 2 / \mathrm{L}$ (Chen et al. 2013). Overall, these results do not demonstrate a particular sensitivity of the gastrointestinal tract or the liver towards silica particles. A reported "brush border disruption" in Caco-2 cells (Yang et al. 2016) after treatment with food-grade silica at concentrations of $0.01,0.1$, and $1 \mathrm{mg} / \mathrm{L}$ for $24 \mathrm{~h}$ is not considered to be of relevance for the in vivo situation where the mucus layer is the major barrier for absorption (Fröhlich and Roblegg 2012). Furthermore, no adverse local effects on the gastrointestinal mucosa have been found in any of the animal studies. In some in vitro experiments with murine macrophages, pyrogenic silica showed effects at lower concentrations than precipitated silica (Di Cristo et al. 2016; Gazzano et al. 2012; Zhang et al. 2012), while there were no significant differences in other cell types, including Caco-2 intestinal or testicular cells (Farcal et al. 2012). The difference tentatively has been ascribed to the complete coverage of precipitated silica with water which would protect the cells from any effect caused by direct contact between particle surface and cell membrane. From further experiments it appears that also a complete dehydroxylation would reduce silica surface reactivity. Any intermediate situation would be more reactive due to the complex interplay between cell membrane and particle surface (Gazzano et al. 2012). Zhang et al. (2012) see the main factor in an energetic unstable condition with 


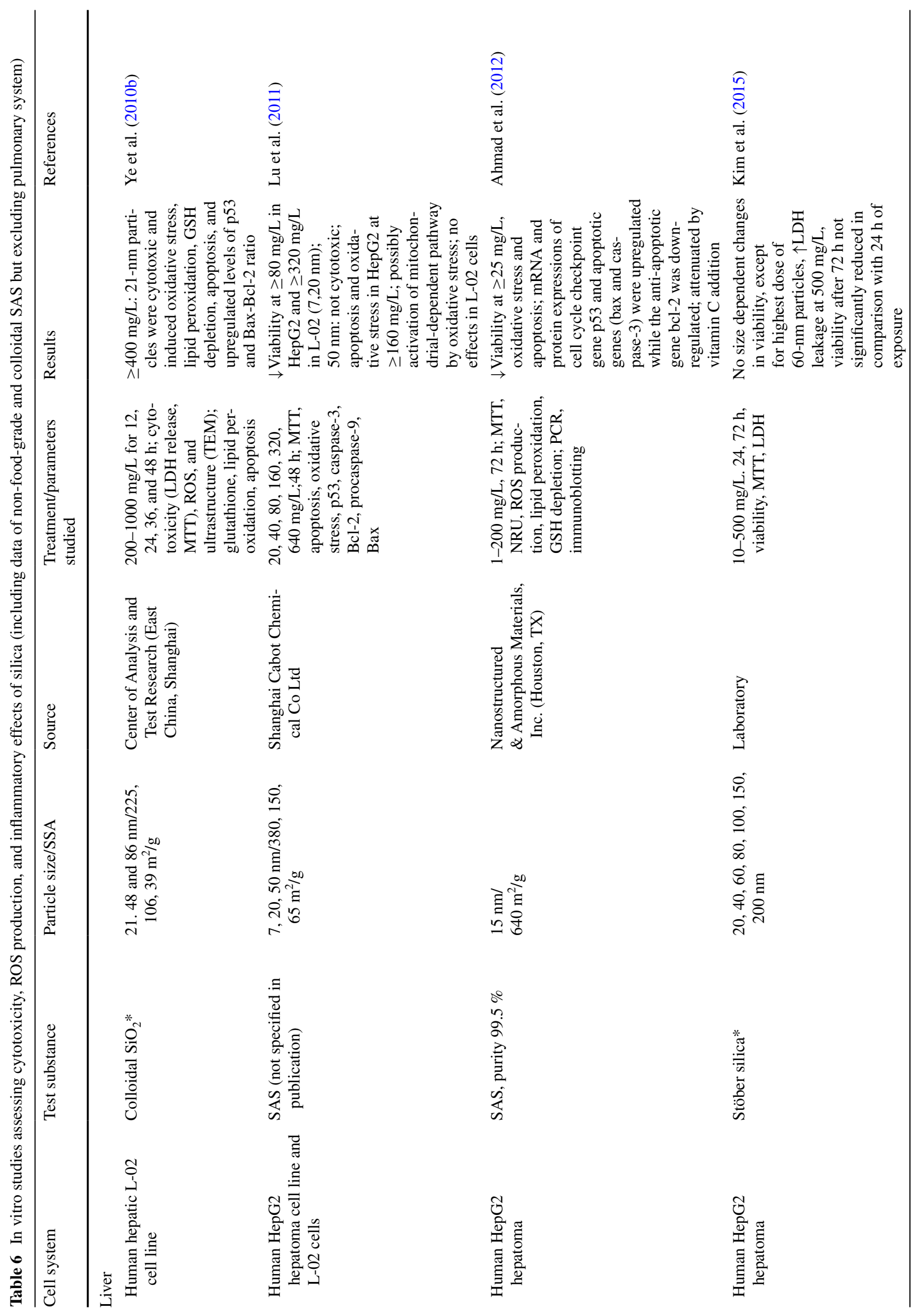




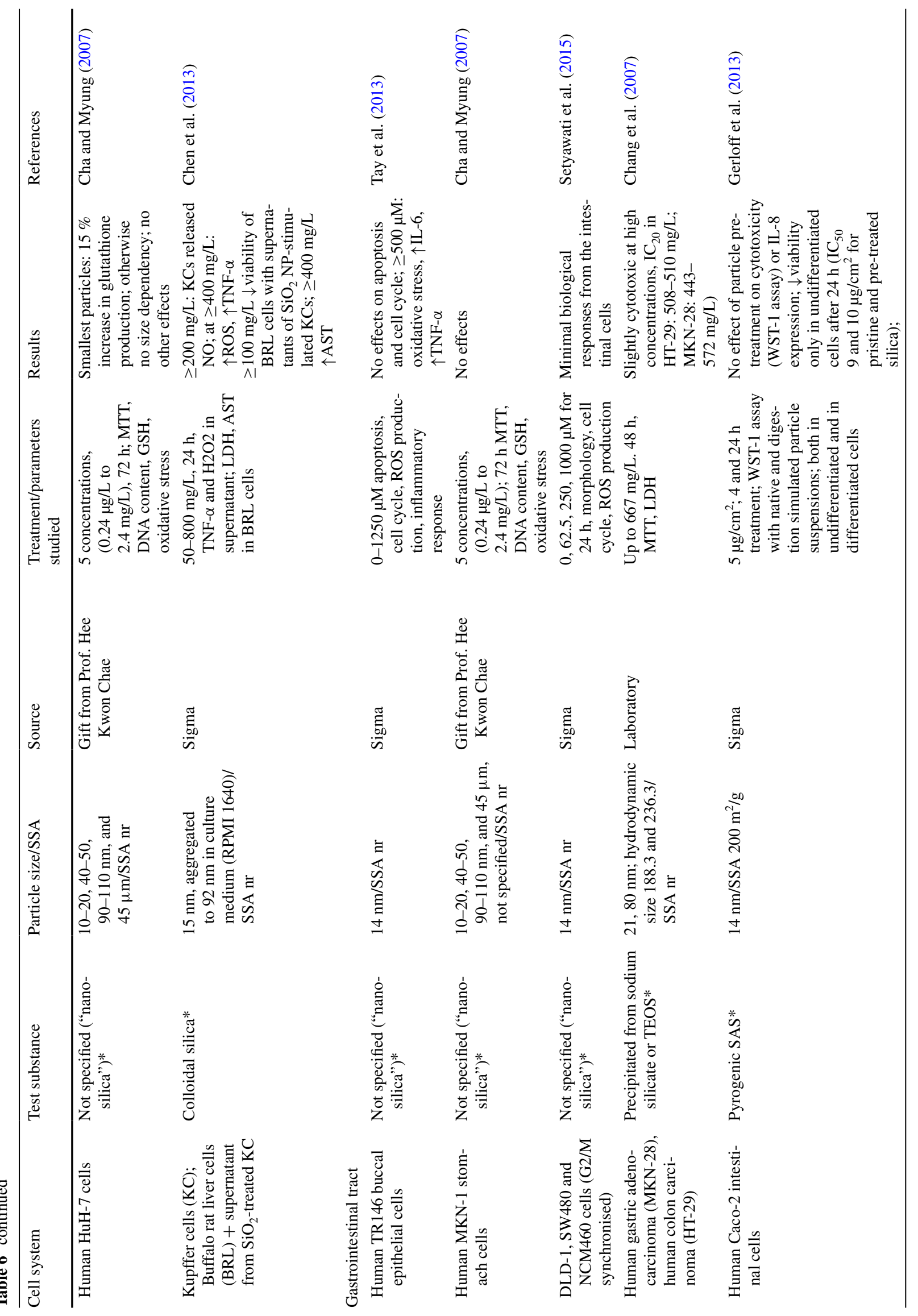




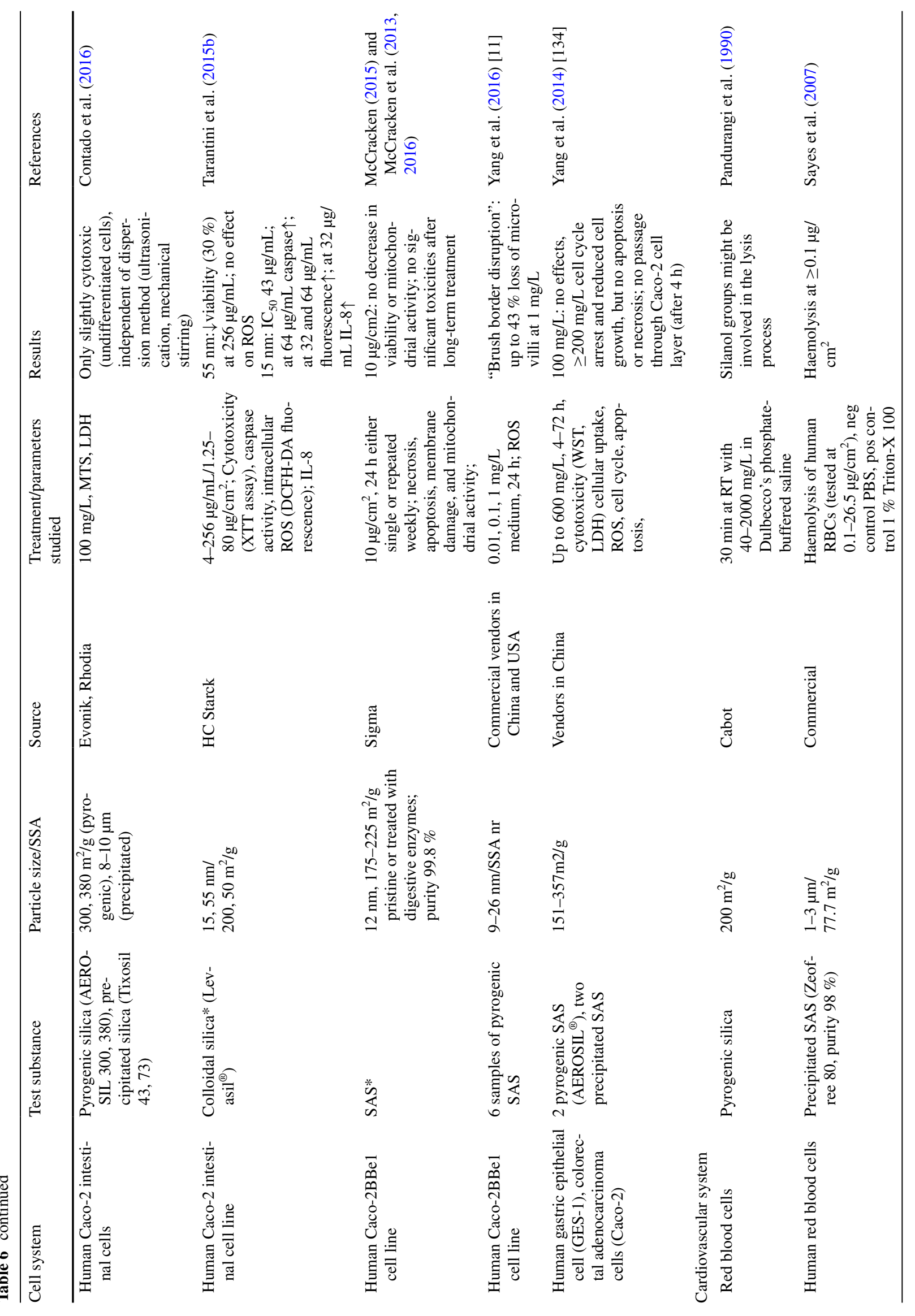




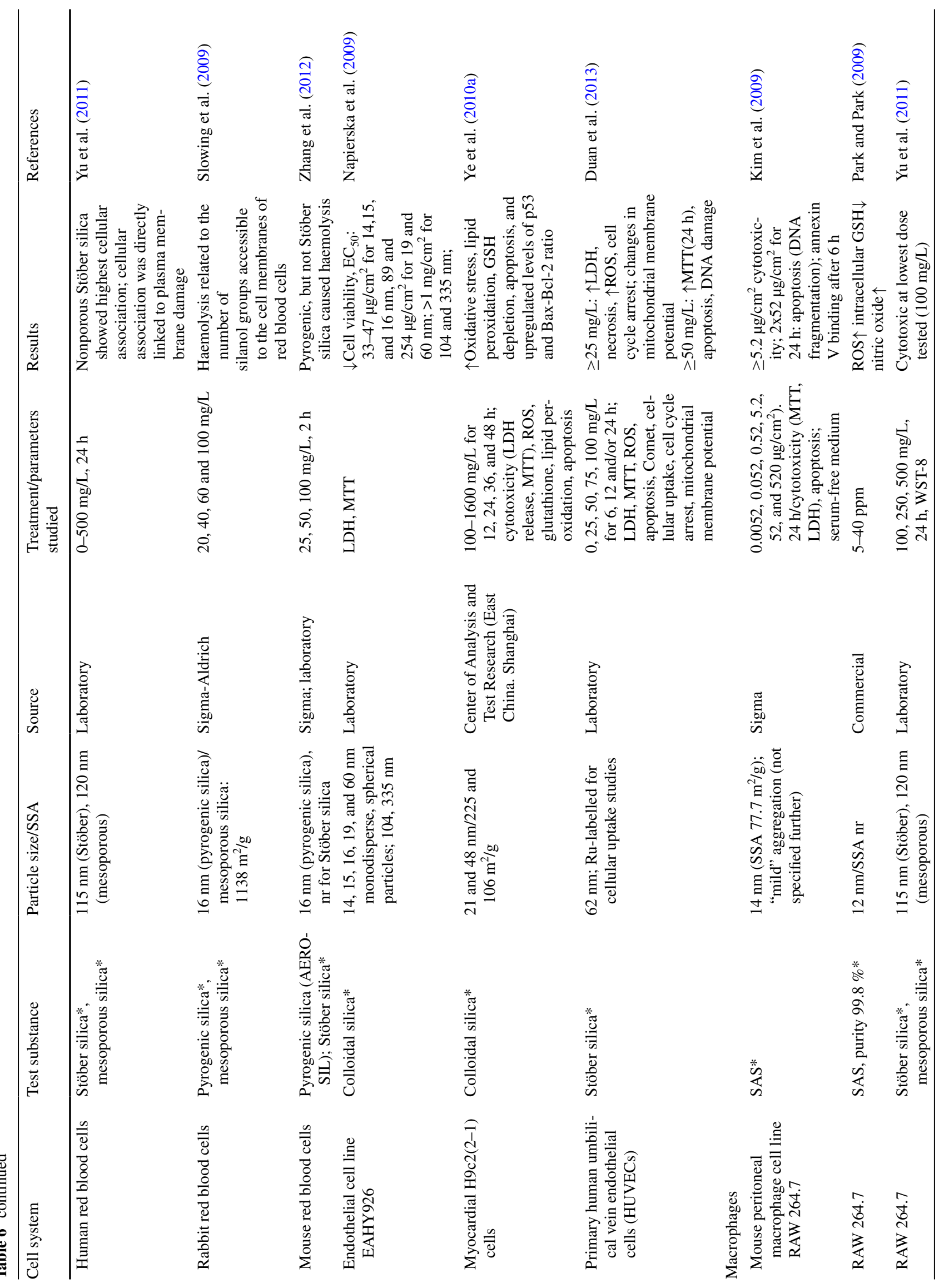




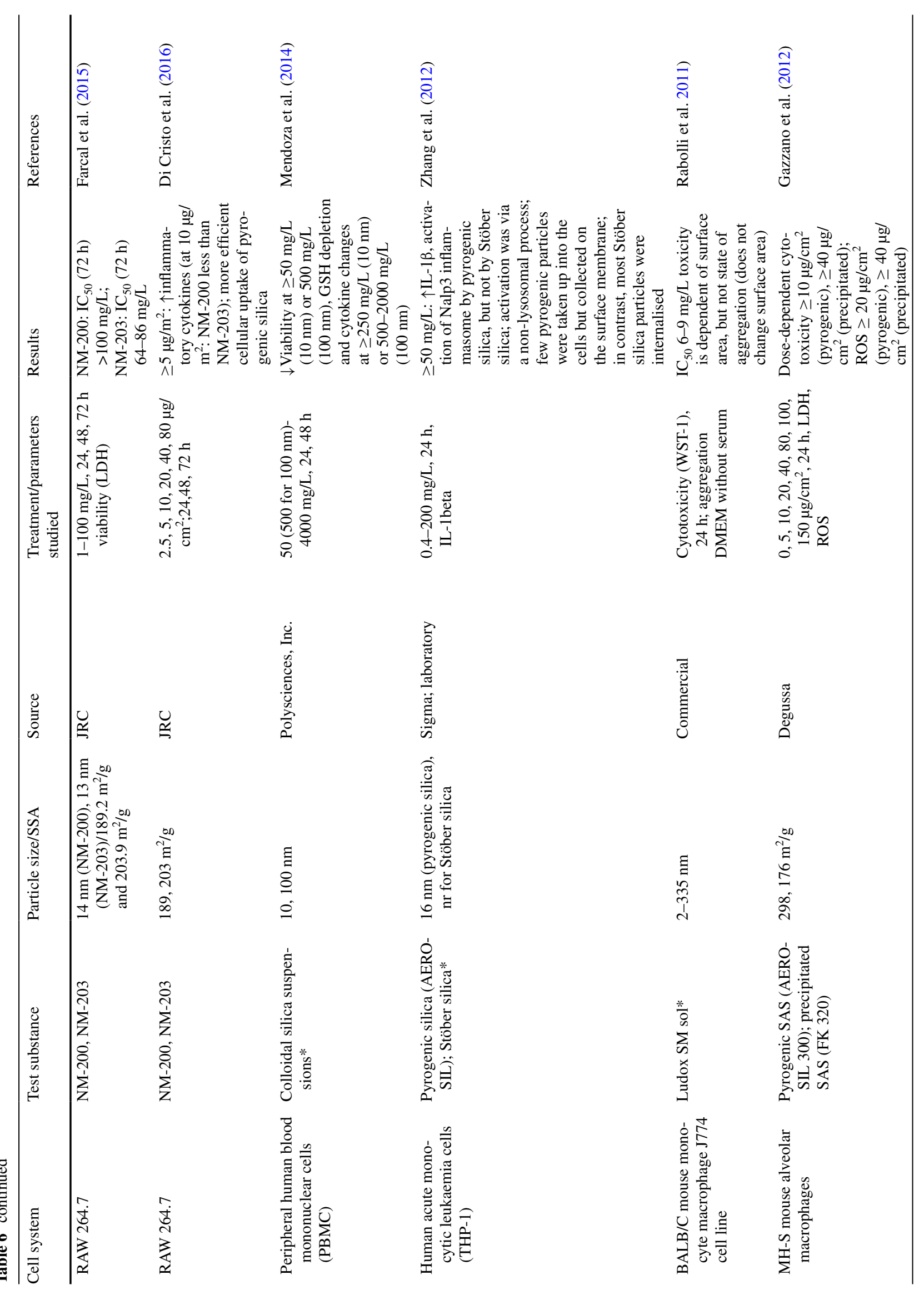




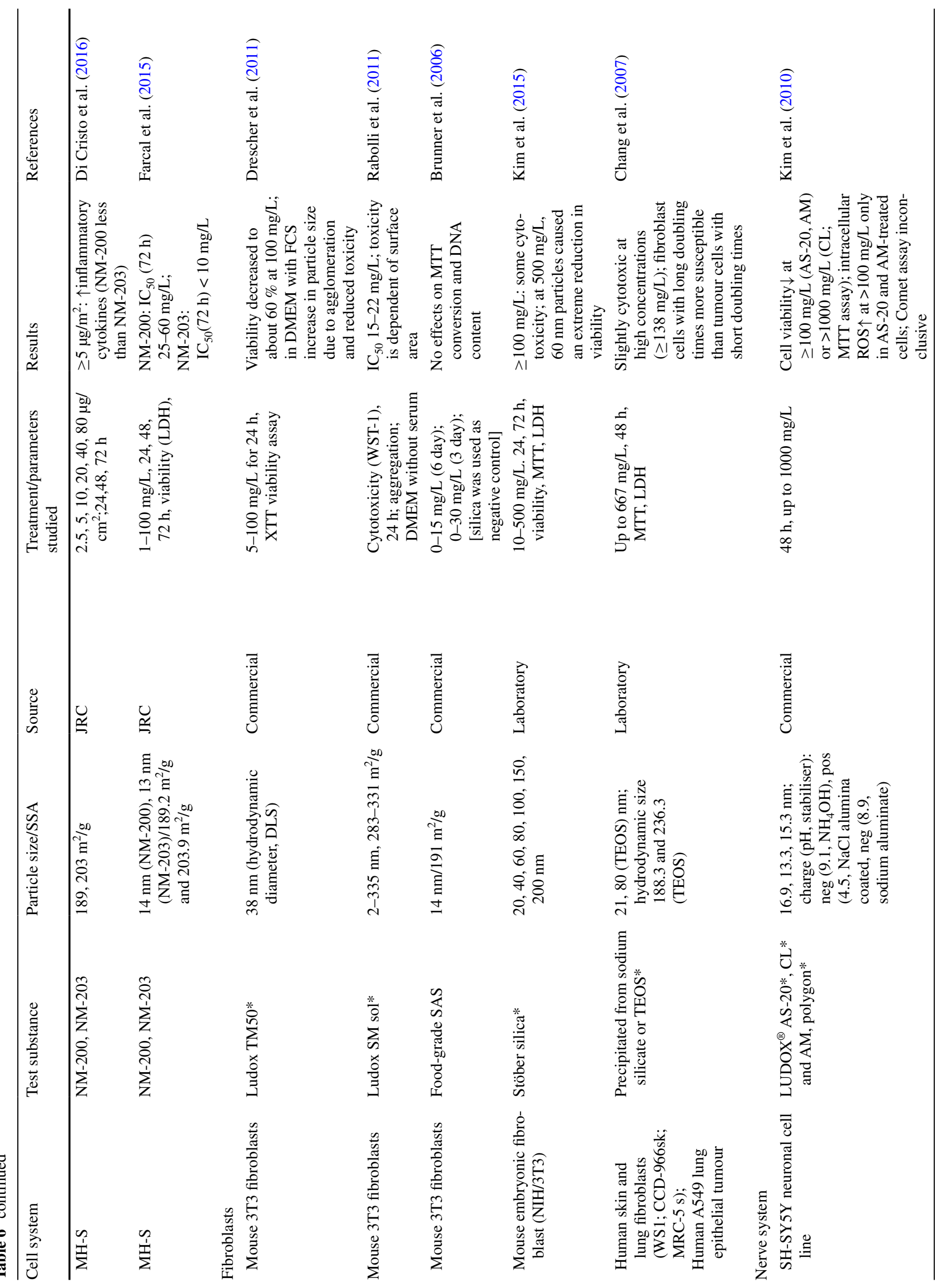




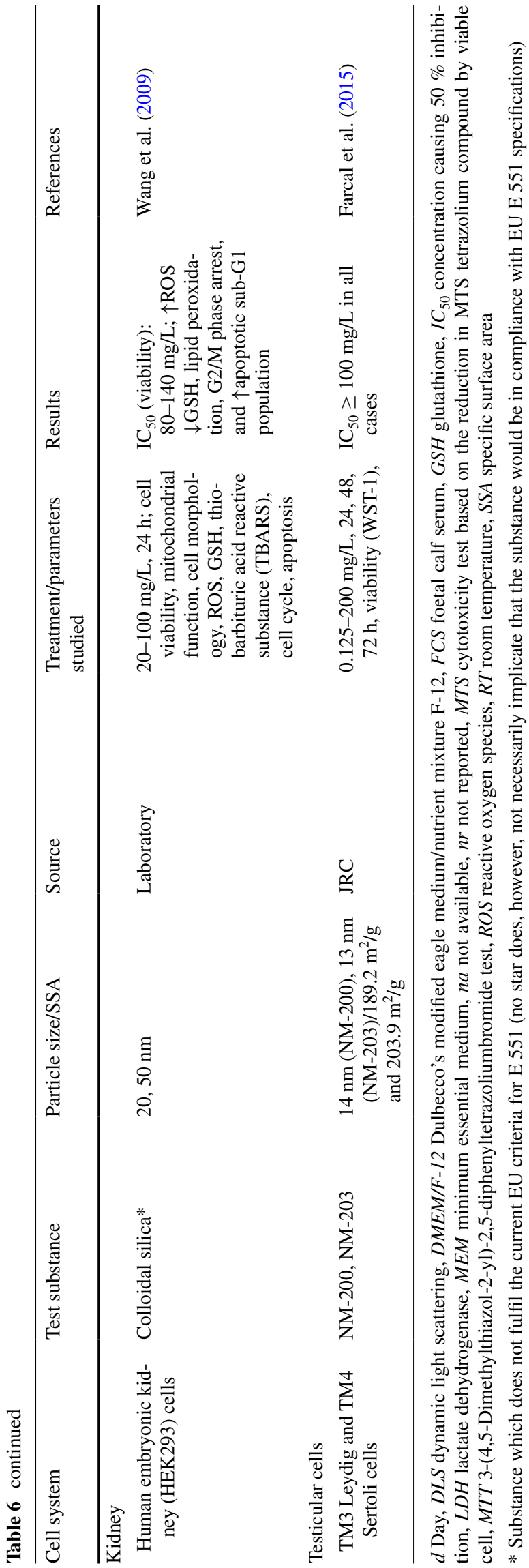

radical formation on the surface of pyrogenic silica. [It is noted that Gazzano et al. did not find evidence of radical formation, neither on the surface of pyrogenic nor that of precipitated silica using electron paramagnetic resonance (EPR)/electron spin resonance (ESR), a suitable method for silica nanomaterials according to an OECD review (OECD 2016)]. Information from in vitro studies with regard to cellular uptake in macrophages is contradictory: in one study it is reported that pyrogenic silica is more efficiently taken up when compared with precipitated silica (Di Cristo et al. 2016); in another study this was not the case (Zhang et al. 2012). Others hypothesise that differences in agglomeration state and solubility are responsible for different biological effects in vitro (Aureli et al. 2012), but there is also evidence to the contrary (Di Cristo et al. 2016; Rabolli et al. 2011). Slight increases in pro-inflammatory cytokines (but no overt toxicity) were observed at $\geq 5 \mu \mathrm{g} / \mathrm{cm}^{2}$ in murine macrophages (cf Table 6). Apart from the fact that the relevance of this in vitro murine model is questionable with regard to humans, see, for example, (Erbel et al. 2013; Mestas and Hughes 2004), the exposure levels were unrealistically high. Even under the assumption of direct contact with the intestinal epithelium (which in fact is protected by a mucous layer and is composed of different cell types) and an intake of up to $1500 \mathrm{mg} /$ day (EFSA 2009), the amount of E 551 in the intestinal lumen would not reach an in vitro effective dose level (taking into account that the mean total mucosal surface of the digestive tract interior averages $32 \mathrm{~m}^{2}$ (Helander and Fandriks 2014), up to $4.6 \mu \mathrm{g} / \mathrm{cm}^{2}$ could theoretically be estimated for the intestinal lumen). The described differences in vitro are therefore not relevant for the in vivo situation after oral exposure to E 551. This is supported by the lack of effects in oral animal studies.

\section{Conclusion}

The systemic availability of E 551 is very low. There is no evidence for the release of nanosized particles in the stomach, but some dissolution and formation of orthosilicic acid may occur in the lower intestinal tract. None of the tested E 551 products caused any adverse local or systemic effect in oral repeated-dose, fertility, and developmental toxicity studies. In particular, there were no signs indicative of liver toxicity or macrophage-induced liver re-modelling even at very high oral doses. There were also no indications of immunotoxicity or neurotoxicity. Reported effects after low-dose exposure to pyrogenic SAS are all within the normal physiological range and cannot be considered as adverse. SAS was not mutagenic or genotoxic in vivo. In intact cells, a direct interaction of unlabelled and unmodified SAS with DNA was never found. Differences in the magnitude of biological responses between pyrogenic and 
precipitated silica described in some in vitro studies with murine macrophages at exaggerated exposures seem to be related to interactions with cell culture proteins and cell membranes. The available toxicological evidence in vivo shows that there is no difference in the toxicity of E 551 products, independent of their manufacturing method. Based on the available evidence, it is concluded that silicon dioxide used as a food additive (E 551) is a substance of very low toxicity which based on the total dietary intake (from its use as a food additive, and its use in dietary supplements) does not represent a human health risk. Any new or novel forms of silicon dioxide that do not comply with established specifications, or are produced to perform a new technological function in food, would require specific safety and risk assessments.

Acknowledgments The preparation of this manuscript was financially supported by the Association of Amorphous Silica Producers (ASASP).

\section{References}

Agir pour l'environnement (2016) Enquête inédite révélant la présence de nanoparticules cachées dans l'alimentation: les pouvoirs publics doivent protéger les consommateurs! Communiqué de presse du 15 juin

Ahmad J, Ahamed M, Akhtar MJ et al (2012) Apoptosis induction by silica nanoparticles mediated through reactive oxygen species in human liver cell line HepG2. Toxicol Appl Pharmacol 259(2):160-168. doi:10.1016/j.taap.2011.12.020

Albers P, Maier M, Reisinger M, Hannebauer B, Weinand R (2015) Physical boundaries within aggregates-differences between amorphous, para-crystalline, and crystalline structures. Cryst Res Technol 50:846-865. doi:10.1002/crat.201500040

Amenta V et al (2015) Regulatory aspects of nanotechnology in the agri/feed/food sector in EU and non-EU countries. Regul Toxicol Pharmacol 73:463-476. doi:10.1016/j.yrtph.2015.06.016

Aureli F, D'Amato M, De Berardis B, Raggi A, Turco AC, Cubadda F (2012) Investigating agglomeration and dissolution of silica nanoparticles in aqueous suspensions by dynamic reaction cell inductively coupled plasma-mass spectrometry in time resolved mode. J Anal At Spectrom 27:1540-1548

Babick F, Mielke J, Wohlleben W, Weigel S, Hodoroaba V-D (2016) How reliably can a material be classified as a nanomaterial? Available particle-sizing techniques at work. J Nanopart Res 18:1-40. doi:10.1007/s11051-016-3461-7

Barahona F, Ojea-Jimenez I, Geiss O, Gilliland D, Barrero-Moreno J (2016) Multimethod approach for the detection and characterisation of food-grade synthetic amorphous silica nanoparticles. J Chromatogr A 1432:92-100. doi:10.1016/j.chroma.2015.12.058

Barnes CA, Elsaesser A, Arkusz J et al (2008) Reproducible comet assay of amorphous silica nanoparticles detects no genotoxicity. Nano Lett 8(9):3069-3074. doi:10.1021/n1801661w

Brunner TJ, Wick P, Manser P et al (2006) In vitro cytotoxicity of oxide nanoparticles: comparison to asbestos, silica, and the effect of particle solubility. Environ Sci Technol 40(14):4374-4381

Buesen R, Landsiedel R, Sauer UG et al (2014) Effects of SiO2, $\mathrm{ZrO} 2$, and $\mathrm{BaSO} 4$ nanomaterials with or without surface functionalization upon 28-day oral exposure to rats. Arch Toxicol 88(10):1881-1906. doi:10.1007/s00204-014-1337-0

Casey TR, Bamforth CW (2010) Silicon in beer and brewing. J Sci Food Agric 90(5):784-788. doi:10.1002/jsfa.3884

CEFIC (2011) 28-day oral toxicity study of synthetic amorphous silica in Wistar (WU) rats. CEFIC Brussels/Belgium

CEFIC (2012a) In vitro mammalian cell gene mutation test in mouse lymphoma L5178Y/TK \pm Cells with synthetic amorphous silica (NM-200). CEFIC Brussels/Belgium

CEFIC (2012b) In vitro mammalian chromosome aberration test (V79 Cells) with synthetic amorphous silica (NM-200). CEFIC Brussels/Belgium

CEFIC (2012c) Measurement of the DNA-damaging and cytotoxic potential of synthetic amorphous silica (NM-200) in cultured primary rat alveolar macrophages. CEFIC Brussels, Belgium

Cha KE, Myung H (2007) Cytotoxic effects of nanoparticles assessed in vitro and in vivo. J Microbiol Biotechnol 17(9):1573-1578

Chang J-S, Chang KLB, Hwang D-F, Kong Z-L (2007) In vitro cytotoxicitiy of silica nanoparticles at high concentrations strongly depends on the metabolic activity type of the cell line. Environ Sci Technol 41(6):2064-2068. doi:10.1021/es062347t

Chen Q, Xue Y, Sun J (2013) Kupffer cell-mediated hepatic injury induced by silica nanoparticles in vitro and in vivo. Int $\mathrm{J}$ Nanomed 8:1129-1140. doi:10.2147/IJN.S42242

Contado C, Mejia J, Lozano Garcia O, Piret JP, Dumortier E, Toussaint O, Lucas S (2016) Physicochemical and toxicological evaluation of silica nanoparticles suitable for food and consumer products collected by following the EC recommendation. Anal Bioanal Chem 408(1):271-286. doi:10.1007/ s00216-015-9101-8

De Jong WH (2012) NANOGENOTOX-Stakeholders workshop:3 May, 2012-Brussels

Decan N, Wu D, Williams A et al (2016) Characterization of in vitro genotoxic, cytotoxic and transcriptomic responses following exposures to amorphous silica of different sizes. Mutat Res/ Genet Toxicol Environ Mutagen 796:8-22. doi:10.1016/j. mrgentox.2015.11.011

Dekkers S et al (2011) Presence and risks of nanosilica in food products. Nanotoxicology 5:393-405

Demir E, Aksakal S, Turna F, Kaya B, Marcos R (2015) In vivo genotoxic effects of four different nano-sizes forms of silica nanoparticles in Drosophila melanogaster. J Hazard Mater 283:260266. doi:10.1016/j.jhazmat.2014.09.029

Di Cristo L et al (2016) Proinflammatory effects of pyrogenic and precipitated amorphous silica nanoparticles in innate immunity cells. Toxicol Sci 150:40-53. doi:10.1093/toxsci/kfv258

Di Felice $\mathrm{G}$ et al (2016) In vivo and in vitro immunotoxicity of $\mathrm{SiO} 2$ nanoparticles. Abstract. 8th International Nanotoxicology Congress. Boston, USA

Downs TR et al (2012) Silica nanoparticles administered at the maximum tolerated dose induce genotoxic effects through an inflammatory reaction while gold nanoparticles do not. Mutat Res 745:38-50. doi:10.1016/j.mrgentox.2012.03.012

Drescher D, Orts-Gil G, Laube G, et al (2011) Toxicity of amorphous silica nanoparticles on eukaryotic cell model is determined by particle agglomeration and serum protein adsorption effects. Anal Bioanal Chem 400:1367-1373

Duan J, Yu Y, Li Y et al (2013) Toxic effect of silica nanoparticles on endothelial cells through DNA damage response via Chk1-dependent G2/M checkpoint. PLoS One 8(4):e62087. doi:10.1371/journal.pone.0062087

Dünisch (2005) Untersuchungen der Wirkungsweise von Nanomaterialien. Dissertation. Universität Würzburg

Dusinska M, Tran L (2015) NanoTEST in a nutshell. Nanotoxicology 9(Suppl 1):1-4. doi:10.3109/17435390.2014.991774 
EC (2007) European Commission. Best available techniques reference document (BREF). Integrated pollution prevention and control. Reference document on best available techniques for the manufacture of large volume inorganic chemicals-solids and others industry. Chapter 5: synthetic amorphous silica. August 2007

ECETOC (2006) European centre for ecotoxicology and toxicology of chemicals. JACC No. 51 "Synthetic amorphous silica (CAS No. 7631-86-9)", Brussels, Belgium

EFSA (2004) European Food Safety Authority. Opinion of the scientific panel on dietetic products, nutrition and allergies on a request from the commission related to the tolerable upper intake level of silicon

EFSA (2009) European Food Safety Authority. Calcium silicate and silicon dioxide/silicic acid gel added for nutritional purposes to food supplements. EFSA J 7:n/a-n/a. doi:10.2903/j. efsa.2009.1132

EFSA (2012) European Food Safety Authority (EFSA) Panel on food additives and nutrient sources added to food (ANS); guidance for submission for food additive evaluations. EFSA J 10(7):2760. doi:10.2903/j.efsa.2012.2760. www.efsa.europa.eu/ efsajournal

Erbel C, Rupp G, Helmes CM, Tyka M, Linden F, Doesch AO et al (2013) An in vitro model to study heterogeneity of human macrophage differentiation and polarization. J Vis Exp 76:e50332. doi: $10.3791 / 50332$

Farcal LR et al (2012) Mechanisms of toxicity induced by $\mathrm{SiO}(2)$ nanoparticles of in vitro human alveolar barrier: effects on cytokine production, oxidative stress induction, surfactant proteins A mRNA expression and nanoparticles uptake. Nanotoxicology. doi $: 10.3109 / 17435390.2012 .710658$

Farcal L et al (2015) Comprehensive in vitro toxicity testing of a panel of representative oxide nanomaterials: first steps towards an intelligent testing strategy. PLoS ONE 10:e0127174. doi:10.1371/journal.pone.0127174

FCRA (2016) Estimation of dietary intakes of Silicon Dioxide (E551) from use as a food additive in Europe. Report provided for Evonik Industries AG. 18th June 2016

Fessard V et al (2016) In Vivo Genotoxicity of SiO2 Nanoparticle after Sub-chronic Oral Exposure. Abstract. 8th International Nanotoxicology Congress. Boston, USA

Fröhlich E, Roblegg E (2012) Models for oral uptake of nanoparticles in consumer products. Toxicology 291:10-17. doi:10.1016/j. tox.2011.11.004

Fruijtier-Pölloth C (2012) The toxicological mode of action and the safety of synthetic amorphous silica-a nanostructured material. Toxicology 294:61-79. doi:10.1016/j. tox.2012.02.001

Gazzano E et al (2012) Physicochemical determinants in the cellular responses to nanostructured amorphous silicas. Toxicol Sci Off J Soc Toxicol 128:158-170. doi:10.1093/toxsci/kfs128

Gehrke H, Frühmesser A, Pelka J et al (2013) In vitro toxicity of amorphous silica nanoparticles in human colon carcinoma cells. Nanotoxicology 7(3):274-293. doi:10.3109/17435390.2011.65 2207

Gerloff K, Albrecht C, Boots AW, Förster I, Schins RPF (2009) Cytotoxicity and oxidative DNA damage by nanoparticles in human intestinal Caco-2 cells. Nanotoxicology 3(4):355-364. doi:10.3109/17435390903276933

Gerloff K (2010) Nanoparticles and the Intestine. Thesis. Heinrich Heine Universität Düsseldorf, Germany

Gerloff K, Pereira DIA, Faria N et al (2013) Influence of simulated gastro-intestinal conditions on particle-induced cytotoxicity and interleukin-8 regulation in differentiated and undifferentiated Caco-2 cells. Nanotoxicology 7:353-366. doi:10.3109/174353 90.2012.662249
Gonzalez L, Thomassen LC, Plas G et al (2010) Exploring the aneugenic and clastogenic potential in the nanosize range: A549 human lung carcinoma cells and amorphous monodisperse silica nanoparticles as models. Nanotoxicology 4:382-395. doi:10.310 9/17435390.2010.501913

Gonzalez L, Lukamowicz-Rajska M, Thomassen LCJ et al (2014) Coassessment of cell cycle and micronucleus frequencies demonstrates the influence of serum on the in vitro genotoxic response to amorphous monodisperse silica nanoparticles of varying sizes. Nanotoxicology 8(8):876-884. doi:10.3109/17435390.2 013.842266

Gray CA, Muranko H (2006) Studies of robustness of industrial aciniform aggregates and agglomerates-carbon black and amorphous silicas: a review amplified by new data. J Occup Environ Med/ Am Coll Occup Environ Med 48:1279-1290. doi:10.1097/01. jom.0000251477.40643.2a

Guichard Y et al (2015) Genotoxicity of synthetic amorphous silica nanoparticles in rats following short-term exposure. Part 2: intratracheal instillation and intravenous injection. Environ Mol Mutagen 56:228-244. doi:10.1002/em.21928

Helander HF, Fandriks L (2014) Surface area of the digestive tractrevisited. Scand J Gastroenterol 49:681-689. doi:10.3109/0036 5521.2014 .898326

Hofmann T, Schneider S, Wolterbeek A, van de Sandt H, Landsiedel R, van Ravenzwaay B (2015) Prenatal toxicity of synthetic amorphous silica nanomaterial in rats. Reprod Toxicol 56:141146. doi:10.1016/j.reprotox.2015.04.006

Howe SE, Lickteig DJ, Plunkett KN, Ryerse JS, Konjufca V (2014) The uptake of soluble and particulate antigens by epithelial cells in the mouse small intestine. PLoS ONE 9:e86656. doi:10.1371/journal.pone.0086656

IARC (1997) International agency for research on cancer. Monographs on the evaluation of carcinogenic risks to humans, Vol 68. Silica. Summary of data reported and evaluation- World Health Organization

Inlivetox (2012) Toxicity of ingested nanoparticles. Development and evaluation of a novel tool for physiologically accurate data generation. EU 7th framework programme report CP-FP 228625-2. Final Publishable Summary Report

Ivanov S, Zhuravsky S, Yukina G, Tomson V, Korolev D, Galagudza M (2012) In vivo toxicity of intravenously administered silica and silicon nanoparticles. Materials 5:1873-1889

Jacobs R, van der Voet H, ter Braak CJF (2015) Integrated probabilistic risk assessment for nanoparticles: the case of nanosilica in food. J Nanopart Res 17:1-14. doi:10.1007/s11051-015-2911-y

Johnston CJ, Driscoll KE, Finkelstein JN et al (2000) Pulmonary chemokine and mutagenic responses in rats after subchronic inhalation of amorphous and crystalline silica. Toxicol Sci 56(2):405-413

JRC (2013) European Commission Joint Research Centre Scientific and Policy Reports. Synthetic Amorphous Silicon Dioxide (NM-200, NM-201, NM-202, NM-203, NM-204): Characterisation and physico-chemical properties. JRC repository: NMseries of representative manufactured nanomaterials. Publications Office of the European Union, Luxembourg

Ju C, Tacke F (2016) Hepatic macrophages in homeostasis and liver diseases: from pathogenesis to novel therapeutic strategies. Cell Mol Immunol 13:316-327. doi:10.1038/cmi.2015.104

Jugdaohsingh R (2007) Silicon and bone health. J Nutr Health Aging 11:99-110

Jugdaohsingh R, Watson AI, Bhattacharya P, van Lenthe GH, Powell JJ (2015) Positive association between serum silicon levels and bone mineral density in female rats following oral silicon supplementation with monomethylsilanetriol. Osteoporos int: a journal established as result of cooperation between the European Foundation for Osteoporosis and the 
National Osteoporosis Foundation of the USA 26:1405-1415. doi:10.1007/s00198-014-3016-7

Jurkić LM, Cepanec I, Pavelić SK, Pavelić K (2013) Biological and therapeutic effects of ortho-silicic acid and some ortho-silicic acid-releasing compounds: new perspectives for therapy. Nutr Metab 10:2-2. doi:10.1186/1743-7075-10-2

Kim HW, Ahn E-K, Jee BK, Yoon H-K, Lee KH, Lim Y (2009) Nanoparticulate-induced toxicity and related mechanism in vitro and in vivo. J Nanopart Res 11(1):55-65. doi:10.1007/s11051-008-9447-3

Kim Y-J, Yu M, Park H-O, Yang S (2010) Comparative study of cytotoxicity, oxidative stress and genotoxicity induced by silica nanomaterials in human neuronal cell line. Mol Cell Toxicol 6(4):336-343. doi:10.1007/s13273-010-0045-y

Kim YR, Lee SY, Lee EJ et al (2014) Toxicity of colloidal silica nanoparticles administered orally for 90 days in rats. Int $\mathrm{J}$ Nanomedicine 9(Suppl 2):67-78. doi:10.2147/ijn.s57925

Kim I-Y, Joachim E, Choi H, Kim K (2015) Toxicity of silica nanoparticles depends on size, dose, and cell type. Nanomed Nanotechnol Biol Med 11(6):1407-1416. doi:10.1016/j. nano.2015.03.004

Klosterkoetter W (1969) Gewerbehygienisches Gutachten ueber die hochdisperse Kieselsaeure "HDK V 15". Unpublished report for Wacker-Chemie. Institut für Hygiene und Arbeitsmedizin

Knebel J, Ziemann C, Creutzenberg OH (2014) CEFIC-LRI N1 Project: Genotoxicity of a synthetic amorphous silica (SAS) in rats. Abstract \#601, The toxicologist

Kwon JY, Kim HL, Lee JY et al (2014) Undetactable levels of genotoxicity of $\mathrm{SiO}(2)$ nanoparticles in in vitro and in vivo tests. Int J Nanomed 9(Suppl 2):173-181. doi:10.2147/IJN.S57933

Kurfe $\beta$ D, Hinrichsen H, Zimmermann I (2005) Statistical model of the powder flow regulation by nanomaterials. Powder Technol 159:63-70. doi:10.1016/j.powtec.2005.06.004

Linsinger T, Roebben G, Gilliland D, Calzolai L, Rossi F, Gibson N, Klein C (2012) Requirements on measurements for the implementation of the European Commission definition of the term "nanomaterial". JRC Reference Reports, European Commission Joint Research Centre

Liu X, Keane MJ, Zhong BZ, Ong TM, Wallace WE (1996) Micronucleus formation in V79 cells treated with respirable silica dispersed in medium and in simulated pulmonary surfactant. Mutat Res 361(2-3):89-94

Lomer MC, Hutchinson C, Volkert S, Greenfield SM, Catterall A, Thompson RP, Powell JJ (2004) Dietary sources of inorganic microparticles and their intake in healthy subjects and patients with Crohn's disease. Br J Nutr 92:947-955

Lu X, Qian J, Zhou H et al (2011) In vitro cytotoxicity and induction of apoptosis by silica nanoparticles in human HepG2 hepatoma cells. Int J Nanomed 6:1889-1901. doi:10.2147/ijn.s24005

Ma-Hock L et al (2007) Generation and characterization of test atmospheres with nanomaterials. Inhal toxicol 19:833-848. doi:10.1080/08958370701479190

Maier M, Hannebauer B, Holldorff H, Albers P (2006) Does lung surfactant promote disaggregation of nanostructured titanium dioxide? J Occup Environ Med/Am Coll Occup Environ Med 48:1314-1320. doi:10.1097/01.jom.0000215405.72714.b2

Maier M, Babick F, Retamal Marin R, Stintz M (2013) Does nanostructured synthetic amorphous silica'disintegrate after oral uptake? Abstract \#1754. The Toxicologist

Maranghi F, Narciso L, Tait S, Martinelli A, Di Virgilio A, Valeri M, Tassinari R (2016) 90-day repeated dose oral toxicity study on synthetic amorphous silica NM 203: the EFSA approach. Poster. 8th International Nanotoxicology Congress. Boston, USA

Maser E, Schulz M, Sauer UG et al (2015) In vitro and in vivo genotoxicity investigations of differently sized amorphous $\mathrm{SiO} 2$ nanomaterials. Mutat Res/Genet Toxicol Environ Mutagen 794:57-74. doi:10.1016/j.mrgentox.2015.10.005

McCracken C (2015) Toxicity of food-relevant nanoparticles in intestinal epithelial models. Dissertation presented in partial fulfillment of the requirements for the degree doctor of Philosophy in the graduate school of The Ohio State University

McCracken C, Zane A, Knight DA, Dutta PK, Waldman WJ (2013) Minimal intestinal epithelial cell toxicity in response to shortand long-term food-relevant inorganic nanoparticle exposure. Chem Res Toxicol 26(10):1514-1525. doi:10.1021/tx400231u

McCracken C, Dutta PK, Waldman WJ (2016) Critical assessment of toxicological effects of ingested nanoparticles. Environ Sci Nano 3(2):256-282. doi:10.1039/C5EN00242G

Mendoza A, Torres-Hernandez JA, Ault JG, Pedersen-Lane JH, Gao D, Lawrence DA (2014) Silica nanoparticles induce oxidative stress and inflammation of human peripheral blood mononuclear cells. Cell Stress Chaperones 19(6):777-790. doi:10.1007/ s12192-014-0502-y

Mestas J, Hughes CCW (2004) Of mice and not men: differences between mouse and human immunology. J Immunol 172:27312738. doi:10.4049/jimmunol.172.5.2731

Mu Q, Hondow NS, Krzemiński Ł, Brown AP, Jeuken LJ, Routledge MN (2012) Mechanism of cellular uptake of genotoxic silica nanoparticles. Part Fibre Toxicol 9(1):1-11. doi:10.1186/1743-8977-9-29

Müller A-K, Ruppel J, Drexel C-P, Zimmermann I (2008) Precipitated silica as flow regulator. Eur J Pharm Sci 34:303-308. doi:10.1016/j.ejps.2008.05.003

NANOGENOTOX (2013) Facilitating the safety evaluation of manufactured nanomaterials by characterising their potential genotoxic hazard. Final publishable report. March 2013. http://www. nanogenotox.eu/

NANoREG (2015) WP 4.5-90d toxiciy study in rats. As presented at the 2015 Annual Congress of the European Environmental Mutagenesis and Genomics Society and at NanoItaly

Napierska D, Thomassen LC, Rabolli V et al (2009) Size-dependent cytotoxicity of monodisperse silica nanoparticles in human endothelial cells. Small 5(7):846-853. doi:10.1002/ smll.200800461

OECD (2004) Screening information data set (SIDS). Synthetic Amorphous Silica and Silicates. Paris

OECD (2016) Organisation for Economic Co-operation and Development. Physical-chemical properties of nanomaterials: Evaluation of methods applied in the OECD-WPMN testing programme. ENV/JM/MONO(2016)7

Pandurangi RS, Seehra MS, Razzaboni BL, Bolsaitis P (1990) Surface and bulk infrared modes of crystalline and amorphous silica particles: a study of the relation of surface structure to cytotoxicity of respirable silica. Environ Health Perspect 86:327-336

Park EJ, Park K (2009) Oxidative stress and pro-inflammatory responses induced by silica nanoparticles in vivo and in vitro. Toxicol Lett 184(1):18-25. doi:10.1016/j.toxlet.2008.10.012

Park MV et al (2009) In vitro developmental toxicity test detects inhibition of stem cell differentiation by silica nanoparticles. Toxicol Appl Pharmacol 240:108-116. doi:10.1016/j. taap.2009.07.019

Park MV, Verharen HW, Zwart E et al (2011) Genotoxicity evaluation of amorphous silica nanoparticles of different sizes using the micronucleus and the plasmid lacZ gene mutation assay. Nanotoxicology 5(2):168-181. doi:10.3109/17435390.2010.506016

Peters R et al (2012) Presence of nano-sized silica during in vitro digestion of foods containing silica as a food additive. ACS Nano 6:2441-2451. doi:10.1021/nn204728k

Poulsen MS, Mose T, Maroun LL, Mathiesen L, Knudsen LE, Rytting E (2015) Kinetics of silica nanoparticles in the human placenta. 
Nanotoxicology 9(Suppl 1):79-86. doi:10.3109/17435390.2013. 812259

Powell JJ et al (2005) A provisional database for the silicon content of foods in the United Kingdom. Br J Nutr 94:804-812

Robberecht H, Van Cauwenbergh R, Van Vlaslaer V, Hermans N (2009) Dietary silicon intake in Belgium: sources, availability from foods, and human serum levels. Sci Total Environ 407(16):4777-4782. doi:10.1016/j.scitotenv.2009.05.019

Rabolli V, Thomassen LC, Uwambayinema F, Martens JA, Lison D (2011) The cytotoxic activity of amorphous silica nanoparticles is mainly influenced by surface area and not by aggregation. Toxicol Lett 206:197-203. doi:10.1016/j.toxlet.2011.07.013

Ruppel J, Müller A-K, Althaus G, Drexel C-P, Zimmermann I (2009) The modified outflow funnel - A device to assess the flow characteristics of powders. Powder Technol 193:87-92. doi:10.1016/j.powtec.2009.02.011

Sakai-Kato K, Hidaka M, Un K, Kawanishi T, Okuda H (2014) Physicochemical properties and in vitro intestinal permeability properties and intestinal cell toxicity of silica particles, performed in simulated gastrointestinal fluids. Biochimica et Biophysica Acta (BBA)—General Subjects 1840:1171-1180. doi:10.1016/j. bbagen.2013.12.014

Sayes CM, Reed KL, Warheit DB (2007) Assessing toxicity of fine and nanoparticles: comparing in vitro measurements to in vivo pulmonary toxicity profiles. Toxicol Sci 97(1):163-180. doi:10.1093/toxsci/kfm018

Sayes CM, Reed KL, Glover KP et al (2010) Changing the dose metric for inhalation toxicity studies: short-term study in rats with engineered aerosolized amorphous silica nanoparticles. Inhalation Toxicol 22(4):348-354. doi:10.3109/08958370903359992

SCCS (2015) EU Scientific Committee on Consumer Safety. Opinion on Silica, Hydrated Silica, and Silica Surface Modified with Alkyl Silylates (nano form) 20 March 2015, SCCS/1545/15, revision of 29 September

Schneider S, Landsiedel R, Wohlleben W, Wolterbeek A, WaalkensBerendsen I, van de Sandt H (2011) Oral prenatal developmental toxicity study with NM-200 synthetic amorphous silica in Wistar rats. Reprod Toxicol 32:173-174. doi:10.1016/j. reprotox.2011.06.102

Sergent JA, Paget V, Chevillard S (2012) Toxicity and genotoxicity of nano-SiO2 on human epithelial intestinal HT-29 cell line. Ann Occup Hyg 56(5):622-630. doi:10.1093/annhyg/mes005

Setyawati MI, Tay CY, Leong DT (2015) Mechanistic investigation of the biological effects of $\mathrm{SiO}_{2}, \mathrm{TiO}_{2}$, and $\mathrm{ZnO}$ nanoparticles on intestinal cells. Small 11(28):3458-3468. doi:10.1002/ smll.201403232

Shumakova AA, Arianova EA, Shipelin VA et al (2014a) Toxicological assessment of nanostructured silica. I. Integral indices, adducts of DNA, tissue thiols and apoptosis in liver. Vopr Pitan 83(3):52-62

Shumakova AA, Avrent'eva LI, Guseva GV et al (2014b) Toxicological assessment of nanostructured silica. II. Enzymatic, biochemical indices, state of antioxidative defence. Vopr Pitan 83(4):58-66

Shumakova AA, Efimochkina NR, Minaeva LP et al (2015) Toxicological assessment of nanostructured silica. III. Microecological, hematological indices, state of cellular immunity. Vopr Pitan 84(4):55-65

Singh G, Stephan C, Westerhoff P, Carlander D, Duncan TV (2014) Measurement methods to detect, characterize, and quantify engineered nanomaterials in food. Compr Rev Food Sci Food Saf 13:693-704

Slowing II, Wu CW, Vivero-Escoto JL, Lin VS (2009) Mesoporous silica nanoparticles for reducing hemolytic activity towards mammalian red blood cells. Small 5(1):57-62. doi:10.1002/ smll.200800926
Takizawa Y, Hirasama F, Noritomi E, Aida M, Tsunoda H, Uesugi S (1988) Oral ingestion of syloid to mice and rats and its chronic toxicity and carcinogenicity. Acta Med Biol $36: 27-56$

Tarantini A et al (2015a) Genotoxicity of synthetic amorphous silica nanoparticles in rats following short-term exposure. Part 1: oral route. Environ Mol Mutagen 56:218-227. doi:10.1002/ em. 21935

Tarantini A et al (2015b) Toxicity, genotoxicity and proinflammatory effects of amorphous nanosilica in the human intestinal Caco-2 cell line. Toxicol In Vitro 29:398-407. doi:10.1016/j. tiv.2014.10.023

Tavares AM et al (2014) Genotoxicity evaluation of nanosized titanium dioxide, synthetic amorphous silica and multi-walled carbon nanotubes in human lymphocytes. Toxicol In Vitro 28:60 69. doi:10.1016/j.tiv.2013.06.009

Tay CY, Fang W, Setyawati MI et al (2013) Reciprocal response of human oral epithelial cells to internalized silica nanoparticles. Part Part Syst Charact 30(9):784-793. doi:10.1002/ ppsc.201300111

Tennant DR (2016) Comprehensive European dietary exposure model (CEDEM) for food additives. Food Addit Contam Part A 33:772-781

Uboldi C, Giudetti G, Broggi F, Gilliland D, Ponti J, Rossi F (2012) Amorphous silica nanoparticles do not induce cytotoxicity, cell transformation or genotoxicity in Balb/3T3 mouse fibroblasts. Mutat Res 745(1-2):11-20. doi:10.1016/j. mrgentox.2011.10.010

van der Zande $M$ et al (2014) Sub-chronic toxicity study in rats orally exposed to nanostructured silica. Part fibre toxicol 11:8. doi:10.1186/1743-8977-11-8

van Kesteren PC, Cubadda F, Bouwmeester H, van Eijkeren JC, Dekkers S, de Jong WH, Oomen AG (2015) Novel insights into the risk assessment of the nanomaterial synthetic amorphous silica, additive E551, in food. Nanotoxicology 9:442-452. doi:10.310 9/17435390.2014.940408

Wang F, Gao F, Lan M, Yuan H, Huang Y, Liu J (2009) Oxidative stress contributes to silica nanoparticle-induced cytotoxicity in human embryonic kidney cells. Toxicol In Vitro 23(5):808-815. doi:10.1016/j.tiv.2009.04.009

Winter M (2010) Immunstimulatorische und immunregulierende Wirkungen von Nanopartikeln und Umweltschadstoffen auf das Darm assoziierte Immunsystem. Inaugural Dissertation. Heinrich Heine Universität Düsseldorf

Winter M, Beer HD, Hornung V, Kramer U, Schins RP, Forster I (2011) Activation of the inflammasome by amorphous silica and $\mathrm{TiO} 2$ nanoparticles in murine dendritic cells. Nanotoxicology 5:326-340. doi:10.3109/17435390.2010.506957

Wolterbeek A et al (2015) Oral two-generation reproduction toxicity study with NM-200 synthetic amorphous silica in Wistar rats. Reprod Toxicol 56:147-154. doi:10.1016/j. reprotox.2015.03.006

Yamashita K et al (2011) Silica and titanium dioxide nanoparticles cause pregnancy complications in mice. Nat Nanotechnol 6:321-328. doi:10.1038/nnano.2011.41

Yang YX et al (2014) Evaluation of the toxicity of food additive silica nanoparticles on gastrointestinal cells. J appl toxicol JAT 34:424-435. doi:10.1002/jat.2962

Yang Y, Faust JJ, Schoepf J, Hristovski K, Capco DG, Herckes P, Westerhoff P (2016) Survey of food-grade silica dioxide nanomaterial occurrence, characterization, human gut impacts and fate across its lifecycle. Sci Total Environ. doi:10.1016/j. scitotenv.2016.01.165

Ye Y, Liu J, Chen M, Sun L, Lan M (2010a) In vitro toxicity of silica nanoparticles in myocardial cells. Environ Toxicol Pharmacol 29(2):131-137. doi:10.1016/j.etap.2009.12.002 
Ye Y, Liu J, Xu J, Sun L, Chen M, Lan M (2010b) Nano-SiO2 induces apoptosis via activation of $\mathrm{p} 53$ and Bax mediated by oxidative stress in human hepatic cell line. Toxicol In Vitro 24(3):751758. doi:10.1016/j.tiv.2010.01.001

Yu T, Malugin A, Ghandehari H (2011) Impact of silica nanoparticle design on cellular toxicity and hemolytic activity. ACS nano 5(7):5717-5728. doi:10.1021/nn2013904

Zhang $\mathrm{H}$ et al (2012) Processing pathway dependence of amorphous silica nanoparticle toxicity: colloidal vs pyrolytic. J Am Chem Soc 134:15790-15804. doi:10.1021/ja304907c
Zhong BZ, Whong WZ, Ong TM (1997) Detection of mineral-dustinduced DNA damage in two mammalian cell lines using the alkaline single cell gel/comet assay. Mutat Res 393(3):181-187

Zijno A, Palamides J, Andreoli C, De Berardis B, Barone F (2016) Genotoxicity Assessment of Silica and Titania on BEAS-2B Cells in the Framework of the EU NANoREG Project. Abstract. 8th International Nanotoxicology Congress. Boston, USA 